

\section{USGS River Ecosystem Modeling: Where Are We, How Did We Get Here, and Where Are We Going?}

\section{A Report from the USGS River Ecosystem Modeling Work Group}

By Leanne Hanson, Robin Schrock, Terry Waddle, Jeff Duda, and Bill Lellis

Scientific Investigations Report 2009-5018 


\section{U.S. Department of the Interior \\ KEN SALAZAR, Secretary \\ U.S. Geological Survey \\ Suzette M. Kimball, Acting Director}

U.S. Geological Survey, Reston, Virginia: 2009

For more information on the USGS - the Federal source for science about the Earth, its natural and living resources, natural hazards, and the environment, visit http://www.usgs.gov or call 1-888-ASK-USGS

For an overview of USGS information products, including maps, imagery, and publications, visit http://www.usgs.gov/pubprod

To order this and other USGS information products, visit http://store.usgs.gov

Any use of trade, product, or firm names is for descriptive purposes only and does not imply endorsement by the U.S. Government.

Although this report is in the public domain, permission must be secured from the individual copyright owners to reproduce any copyrighted materials contained within this report.

Suggested citation:

Hanson, L., Schrock, R., Waddle, T.J., Duda, J.J., and Lellis, W.A., 2009, USGS river ecosystem modeling —Where are we, how did we get here, and where are we going? A report from the USGS River Ecosystem Modeling Work Group: U.S. Geological Survey Scientific Investigations Report 2009-5018, 81 p. 


\section{Contents}

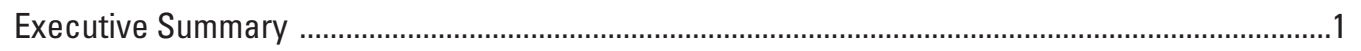

River Ecosystem Modeling Work Group Recommendations ...............................................................

River Ecosystem Modeling Work Group Summary .............................................................................2

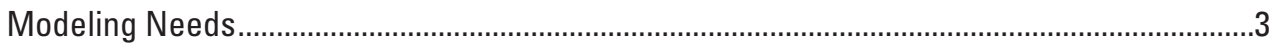

Model Selection Criteria ....................................................................................................

Prototype Study Area Selection Criteria ............................................................................

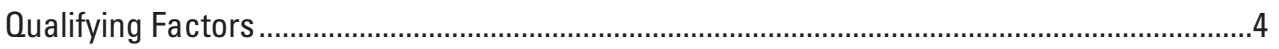

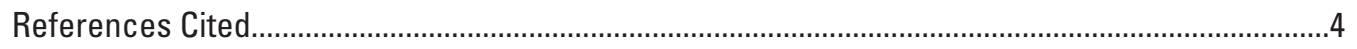

Appendix 1. River Ecosystem Modeling Work Group Agenda .....................................................5

Appendix 2. River Ecosystem Modeling Break Out Group Instructions ............................................6

Appendix 3. River Ecosystem Modeling Break Out Group Notes ......................................................

Appendix 4. River Ecosystem Modeling Work Group Participants and Contributors ........................9

Appendix 5. Model Summary Sheets ...........................................................................................13 



\title{
USGS River Ecosystem Modeling: Where Are We, How Did We Get Here, and Where Are We Going?
}

\section{A Report from the USGS River Ecosystem Modeling Work Group}

\author{
By Leanne Hanson, Robin Schrock, Terry Waddle, Jeff Duda, and Bill Lellis
}

\section{Executive Summary}

As the Nation's unbiased science bureau within the Department of the Interior, the U.S. Geological Survey (USGS) is well-situated to provide science in support of current and future river resource management decisions. The information gained through USGS research and monitoring efforts affects management actions and decisions which, in turn, benefit society. As anthropogenic actions and variations in natural systems continue, it is more important than ever to understand the effects of change on natural systems. Through the ongoing commitment of agency resources to riverine science, the USGS will continue to build upon nearly a century of natural systems research, monitoring, and modeling.

The USGS can become more efficient through better use of current human and technologic resources, but still remain a leader in riverine modeling through increased communication opportunities and a national infrastructure for modeling resources. Scientists with the USGS have proven competence in developing and applying individual models, and many have contacts with modelers outside of the USGS, but it is time for a systematic means of capitalizing on those contacts across the Bureau. The Work Group identified the need for a centralized, online menu of available modelers and modelsincluding a description of model capabilities, a list of model limitations, and references for model application examples. Included in appendix 5 is the start of this USGS modeling menu. The summary sheets of the 60 models currently being used for river ecosystem modeling within the USGS should be expanded, continually updated, and made accessible online to foster scientific collaboration.

Managers, scientists, and policy makers need predictive models that can describe changes in temporal and spatial attributes of rivers under human influence while acknowledging the uncertainty of natural dynamic change. Incorporating current knowledge of global climate change and increasing natural and induced hazards into new, integrated models will provide valuable risk assessment and decision support tools for adaptive management of natural and managed riverine ecosystems. This Work Group report includes suggestions and criteria for implementing a strategy for integrated modeling within the USGS.

\section{River Ecosystem Modeling Work Group Recommendations}

Work Group recommendations include enhancing communications, achieving increased efficiency through better use of current human and technologic resources, and providing a national infrastructure for our modeling resources, which would make it easier to integrate modeling efforts and continue to build upon nearly a century of natural systems research, monitoring, and modeling for which the USGS is known.

These recommendations require organization and coordination across USGS disciplines and regions. Enhanced communications can be achieved through USGS funding of, maintaining, and providing access to online resources such as the model summary sheets included in appendix 5 , electronic chat, and bulletin boards focused on river ecosystem modeling, as well as through USGS-sponsored national meetings and conferences focused on river ecosystem modeling. These efforts, developed across disciplines and regions, will allow for easier communication within the USGS modeling community and ultimately will result in enhanced multidisciplinary, integrated model development. 


\section{River Ecosystem Modeling Work Group Summary}

This document was developed as an outcome of the USGS River Ecosystem Modeling Work Group. This Work Group was held on Monday, February 11, 2008, as a preconference session to the second USGS Modeling Conference in Orange Beach, Ala. The Work Group agenda (appendix 1) was organized so that participants would first gain a better understanding of the types of models currently being applied to riverine studies within the USGS, then learn about how model outputs are being used by a land management agency, and then use this information during the break-out group session to develop recommendations for advancing the state of the art in river ecosystem modeling within the USGS.

One tool developed and distributed to participants before the February 11 session, to help assess the types of models currently being used in river ecosystem modeling in the USGS, was simply a summary list of models. Modelers across the USGS were contacted (appendix 4) and asked to submit a summary sheet for each of the models they currently use or are developing for use in river ecosystem modeling. This survey resulted in the list of 60 models included in appendix 5; the summaries include statistical models, surface- and groundwater models, visualization programs, watershed models, 1-dimension transport models, and 1-dimension, 2-dimension and 3-dimension hydraulic models. While this list is a start, Work Group participants supported the idea that this list be expanded, continually updated, and made available online to foster collaboration among modelers.

A major portion of time during the River Ecosystem Modeling Work Group was devoted to break-out group discussions and development of recommendations for consideration by USGS management. Each break-out group was given the goal of developing a prioritized list of what direction the USGS should take in river ecosystem modeling (appendix 2). In order to help the groups develop and prioritize suggestions, they were given the following discussion points and criteria for establishing priorities for their suggestions.

\section{Discussion Points:}

- Identify current and future modeling needs.

- Describe how current models or current model developments fill those needs.

- Identify gaps between current models and those needs.

- Establish priorities for work on the areas of greatest need.

\section{Priority Setting Criteria:}

1. Magnitude of the issue that the model will addressthe scope (geographic and societal benefits) of issues addressed by this model. (For example, this model category will deal with global climate issues across the world's rivers.)

2. Extent of gap between the current state of the art and the need - how far is our computing power behind our data generating capacity? (For example, we have a hydrodynamic model of a 10 -mile river reach at a $1 \mathrm{~cm}$ resolution, but we do not have the computing power to process the data. Or, we are currently unable to predict aquatic species populations in streams under stable conditions, nor in a changing stream state, therefore we would be filling a large, important gap in modeling.)

3. Current urgency of the need - managers need tools to answer immediate needs.

The discussion points lead the break out groups to restate many of the recommendations that came out of the first USGS Modeling Conference and previous USGS needs assessment activities. Specifically discussed were River Ecosystem Modeling topics outlined in:

1. River Science at the U.S. Geological Survey (National Research Council, 2007),

2. Science for Maintaining Riverine Ecosystems: Actions for the USGS Identified in the Workshop "Analysis of Flow and Habitat for Aquatic Communities" (Bencala and others, 2006),

3. Linking Hydrological Change and Ecological Response in Streams and Rivers of the Eastern United States (U.S. Geological Survey, 2005b), and

4. Three discussion papers included in the first All-USGS Modeling Conference Summary Report (U.S. Geological Survey, 2005a):

a. Technical Needs: Linking Models into a Multimodel Framework,

b. Integrating the Interagency and Interdisciplinary Community, and

c. The Data-Model Connection: Model Testing, Sensitivity Analysis, Calibration, and Uncertainty Evaluation.

Work Group participants reaffirmed and supported the recommendations from the first USGS modeling conference:

- Increase communication among the USGS modeling community,

- Establish modeling Center of Excellence,

- Participate in Interagency Modeling Collaborations,

- Plan subsequent workshops to refine and implement USGS Modeling Strategy, and 
- Provide infrastructure to support USGS Modeling Strategy.

Discussion of the first modeling conference recommendations revealed that (1) the distributed nature of river modeling efforts within the USGS speaks to the need for better coordination, (2) USGS scientists are competent in developing and applying individual models, and (3) individuals have contacts with modelers outside the USGS but there is no systematic means of capitalizing on those contacts across the Bureau. In this report, we develop suggestions for implementing a strategy for integrated river ecosystem modeling within the USGS by focusing on a resource management problem, with the intent to bring together the interdisciplinary resource knowledge and modeling talent needed to accomplish such integration.

\section{Modeling Needs}

In evaluating how models can help address resource problems, we identified a body of modeling needs and gaps (appendix 3). Among them are the needs to:

1. Tie global climate models and expectation of change to other models, that is, step global change predictions down to regional and river basin levels,

2. Identify historical biological response to changes in rivers by using models to backcast legacy effects of chronic and acute bottleneck disturbances,

3. Use such information about changes over recent decades to predict what river ecosystems will look like in the future,

4. Extend and integrate process models to address these kinds of synergistic questions,

5. Develop models that can accommodate several scales or 'autoscale' to the scope of the problem being addressed, and

6. Establish better tools for communicating models and their results to the modeling community, natural resource managers, and decision and policy makers.

We decided to move forward from this point to suggest a strategy for demonstrating and advancing the Bureau's modeling capabilities. We believe we can work together toward an integrated river ecosystem model capability, but until we face a common problem we will not effectively integrate our models and make progress. The process of addressing river ecosystems, by its nature, requires model development and integration to be conducted by interdisciplinary teams. We identified a two-tiered strategy to assist with selecting models and problems for which to apply the models.

\section{Model Selection Criteria}

The first tier was to establish criteria for selecting models for further integrated model development. These criteria included:

1. Model(s) addresses real world problems. Model is applicable to relevant natural resource policy or societal needs.

2. Model(s) has been validated, or its use is widely accepted.

3. Model(s) is being integrated or is ripe for integration.

4. Model(s) has an associated and quantifiable level of confidence associated with it, or tests of confidence have been described and can be included in pilot project.

5. Model(s) fits needs of the USGS in its role as lead science agency.

6. Model(s) addresses important knowledge/science gap.

The second tier involves developing a prototype integrated modeling project. Potential projects would be evaluated using the above criteria, leading to a demonstration project in a real location, selected based upon criteria listed below. Experience of modelers present suggested that the ideal way for model development (or integration) to proceed is to work on an actual problem, rather than work on a 'conceptual framework' for integration. A live project will generate more interest than a concept and, by illuminating specific challenges, spur more model development. The product of such an effort will be a set of integrated physical and biological models and the interfacing mechanism linking them. The linking interface will allow for future expansion.

\section{Prototype Study Area Selection Criteria}

Thus there is a need to find a ripe problem to be a focal mechanism to get interdisciplinary work started in the USGS. Criteria for choosing a location for a future Bureau-level, multidisciplinary modeling demonstration project include:

1. Area has existing data (for example, data rich, watershedwide information, both physical and biological parameters covered).

2. Area has identified knowledge gaps best answered by a modeling solution. 
3. Area has a modeling question that requires model integration. Difficulty of integration will challenge and strengthen model development.

4. Area has a focal problem that has regional or national significance, so that results of integrated modeling effort could be utilized elsewhere.

5. Problem(s) addressed in the area requires predictive or forecasting capabilities.

6. Area has issues that are relevant to the public and policy makers. There is a mild level of urgency driving willingness to attack the problem, but the issues are not so politically polarized as to prohibit application of modeling outcome.

7. Area or problem was identified in the previous Water Availability Initiative.

8. Area has interested Federal partners.

9. Area has the ability to establish quasi-experimental conditions (for example, a way to control forcing functions).

The selection of an area for a demonstration project will be based upon a ranking using the above criteria. No area of the country is expected to satisfy all of these criteria, so a candidate area would not be excluded because of a lack of one or more criteria. The criteria should also be weighted, with emphasis on strong opportunity to either serve an important decision or to advance model integration. For example, items $3,4,6,7$, and 8 could be weighted more heavily than the other items to reflect this emphasis.

\section{Qualifying Factors}

Other factors to consider when evaluating the selection of demonstration projects include determining:

- the data needs of the models, especially in terms of resolution and frequency,

- additional data requirements that would arise with the project,

- the source of funding for the data collection/synthesis/ modeling effort, and

- the time frame the product would need to meet in order to be approved.

Several potential river basins were discussed as candidates, but the group expressed concern that creating a short list of potential basins matching these criteria at this time may act to focus on the location rather than further the cause of integrated model development.
Support for models comes from their perceived utility, often based on a combination of the relevance of the model to the decisions being faced and the relative user friendliness of the models. Model developers need to consider the users both through visual display of model inputs and results and through interpretive modules such as decision support systems (which may be models in themselves) that deliver model results in the language and context of the decisions being faced.

The group discussed potential means to implement this recommendation. Possible mechanisms included integrating it into the Climate Change Initiative, arguing that modeling expertise is amply available within the USGS but there is a need for focus and management support, and presenting this paper to the Regional Executives as an opportunity to address one or more pressing problems in their respective regions. The group identified the need for a centralized menu of available models including a description of what the model does, a list of model limitations, and references to model application examples.

These considerations led to our recommendation: Select a river system with an important ecosystem/management problem and enable a multidisciplinary team to integrate models to address the problem. Implementing this recommendation will have the effect of furthering several goals defined in the first USGS modeling conference through a concrete model application process that will encourage increased communication among the USGS modeling community, involve interagency collaboration, and expand our capabilities.

\section{References Cited}

Bencala, K.E., Hamilton, D.B., and Petersen, J.H., 2006, Science for managing riverine ecosystems-Actions for the USGS identified in the workshop "Analysis of flow and habitat for instream aquatic communities": U.S. Geological Survey Open-File Report 2006-1256, http://pubs.usgs.gov/ of $/ 2006 / 1256 /$.

National Resource Council, 2007, River science at the U.S. Geological Survey: Washington, D.C., National Academies Press for the National Research Council Water Science and Technology Board, Committee on River Science at the U.S. Geological Survey, 206 p., http://www.nap.edu/catalog. php?record_id $=11773$ \#orgs.

U.S. Geological Survey, 2005a, All-USGS Modeling Conference, 1, Port Angeles, Wash., 14-17 November 2005: U.S. Geological Survey Internal Management Report, 47 p.

U.S. Geological Survey, 2005b, Linking hydrological change and ecological response in streams and rivers of the eastern United States, Herndon, Va., 8-10 February 2005, Proceedings: U.S. Geological Survey Northern Appalachian Research Laboratory, http://www.lsc.usgs.gov/NARB/workshops/2005/index.html. 


\section{Appendix 1. River Ecosystem Modeling Work Group Agenda}

USGS River Ecosystem Modeling:

Where are we, how did we get here, and where are we going?

February 11, 2008

8:30 am - 5:00 pm

Agenda

8:30 am Introduction and Goals for Day - Leanne Hanson

8:45 am Summary Presentations (15 minute overview/highlights)

Policy Impacts - Nina Burkardt

Hydrodynamics and Sediment Transport - Jonathan Nelson/ Rich McDonald

Ecosystem Models - Mary Freeman

Water Quality Models - Jerad Bales

Instream Flow and Decision Support Systems - Terry Waddle

10:00 am - Break

10:15 am - Robert Deibel, U.S. Forest Service, National Instream Flow Coordinator Customer Needs/Expectations

11:00 am - Re-Cap Work Group Goals and Direction - Leanne Hanson

11:45 am - Lunch on your own

12:45 pm - Facilitated Breakout Groups

5-6 groups having focused discussions based on provided White Paper Outline.

See Break-out Group Instructions below

3:00 pm - Break

3:15 pm - Meeting Wrap-up

Group Discussion:

Understanding Gained from Break-out Group Participation

Interesting Model Stories (this only happened because...)

What Makes a 'Good' Model Good...

\section{4:30 pm - Making Linkages and What Will Happen Next - Leanne Hanson}

Full group discussion to develop recommendations of how work group findings link-up.

Next steps for the group, information, and insights gleaned from this Session.

5:00 pm - Meeting Adjourns 


\title{
Appendix 2. River Ecosystem Modeling Break Out Group Instructions
}

\author{
USGS River Ecosystem Modeling: \\ Where are we, how did we get here, and where are we going? \\ February 11, 2008
}

Break-out Group Instructions

Break-out Group Topic (check one):

Policy

Hydrodynamics and Sediment Transport

Ecosystems

Water Quality

Instream Flow and Decision Support Systems

Group Recorder:

Name

E-mail Address

Please list group participant names on back of sheet.

Goal:

Develop a prioritized list of what river ecosystem modeling (in your topic area) should be done within USGS.

Discussion Points:

- Identify current and future modeling needs

- Describe how current models or current model development fills those needs

- Identify gaps between current models and those needs

- Establish priorities for work on the areas of greatest need

For each discussion point list developed, please identify which criteria was used to establish the priority.

\section{Priority Setting Criteria:}

1. Magnitude of issue that the model will address - the scope (geographic and societal benefits) of issues addressed by this model (i.e., this model category will deal with global warming issues across the World's Rivers).

2. Extent of gap of the current state of the art from the need - how far behind the eight-ball are we? (i.e., we need a hydrodynamic model of a 10 mile river reach at a $1 \mathrm{~cm}$ resolution, but we don't have the computing power to process the data. Currently we are unable to predict aquatic species populations in streams under stable conditions, let alone in a changing stream state, therefore we are filling a large, important gap in modeling).

3. Current urgency of the need - can you get me an answer by Friday? (i.e., the resource needs a heart transplant, but we don't have a heart [model] available). 


\section{Appendix 3. River Ecosystem Modeling Break Out Group Notes}

Models are only as reliable as the data used to drive them. The group identified several kinds of information needs in terms of specific data and knowledge needed about ecological processes. This summary of those items may be useful in informing the USGS science strategy document on water availability being prepared this quarter and funding allocation discussions as they may occur.

- $\quad$ are we talking about developing a model or applying a model? - This comment speaks to the use of models to test hypotheses. In some cases a site-specific or case-specific model may be needed to test a hypothesis prior to developing a deterministic or stochastic representation of the phenomena.

- $\quad$ people in the field are not necessarily aware of models and their applications - This speaks to the need for a broader mechanism by which model availability is communicated to the USGS community and to our partner natural resource agencies.

- What questions do we want to address? What data do we need to develop those tools? What level of confidence do you want in those models? - These points need to be brought up in discussing any prototype study case.

No one model, or group of models, can incorporate all of the variability in natural systems, especially as we learn more about the complexities of these systems. The break out group identified the following gaps and challenges in river ecosystem modeling:

- Biological - Ecological 'Response'

○ Look at biologic and phylogenic response with models-we need to look at biota and organic components of aquatic systems and identify the historical biological response with molecular techniques

- Look at legacy effects of bottleneck disturbance; USGS has at least two molecular labs. We should be looking at microsatellite markers (mt) of DNA-to analyze gene flow vs. historical landscape changes

$\circ \quad$ Need follow-up to validate the models we have now.

- $\quad$ Long term data sets are key...

- Need a better process for understanding the physical and ecological mechanisms at work

- Use information and data on how systems have changed over recent decades to make predictions of what systems will look like in the future?

- Specific ecological outcomes

- Channel change models

- Water sources will change (e.g., wastewater inputs to systems)

$\circ \quad$ Water quality models

○ Scale

- Changes of water quality affects on biotic communities

- Stream temperature

- Biotic and physical response?

- Anyone asking for this yet?

- Land use change and effect on systems?

- Do we assume unchanged development practices?

- Play with this in models - effects of differing management practices

$\circ$ How much data to pull this apart? Site-specific data; across a basin - harder

- Land use change + Climate change

- Including sea level change

$\circ$ What synergies exist between these?

- System-scale change - Integrating models of ecosystem components to characterize current/past/future ecological conditions

- Flow

- Water quality

$\circ$ Biologic structure 
Our one last note:

We considered a modeling motto similar to the science motto "Science is not science until it's published". Perhaps we should say, "A model is not a model until it's transferred to the user." Thus, an additional condition for development of a potential prototype river ecosystem problem would be the existence of a body of interested users. 


\section{Appendix 4. River Ecosystem Modeling Work Group Participants and Contributors}

This appendix contains the names, phone numbers, and affiliations of work group participants and those individuals who were included in e-mail traffic related to the river ecosystem modeling work group but were unable to participate in the work group in person.

\begin{tabular}{|c|c|c|}
\hline Full name & Phone number & Affiliation \\
\hline Andrea Alpine & 928.556 .7094 & BRD-HQ \\
\hline Dave Armstrong & 508.490 .5060 & WRD-ER-MA \\
\hline Guleid Artan & 605.594 .6195 & Geog \\
\hline Terry Arundel & 928.556 .7174 & BRD-SBSC \\
\hline William Asquith & 512.927 .3580 & WRD-TX \\
\hline Greg Auble & 970.226 .9448 & BRD-FORT \\
\hline Jerad Bales & 919.571 .4048 & WRD-NC \\
\hline Larry Barber & 303.541 .3039 & WRD \\
\hline Doug Beard & 703.648 .4215 & BRD-HQ \\
\hline Jayne Belnap & 435.719 .2333 & BRD-SBSC \\
\hline Ken Bencala & 650.329 .4409 & WRD-WR-NRP \\
\hline Charles Berenbrock & 703.648 .6876 & WRD-OSW \\
\hline Steve Blanchard & 703.648 .5629 & WRD-HQ \\
\hline Kyle Blasch & 520.670 .6671 ext 283 & WRD \\
\hline Dave Bornholdt & 304.724 .4502 & USGS-ER \\
\hline Ken Bovee & 970.226 .9320 & BRD-FORT \\
\hline Zack Bowen & 970.226 .9218 & BRD-FORT \\
\hline Bret Bruce & 303.445 .4613 & WRD-CRO \\
\hline Janice Bryan & 573.441 .2953 & BRD \\
\hline Nina Burkardt & 970.226 .9275 & BRD-FORT \\
\hline Dave Busch & 503.808 .2192 & USGS-WR \\
\hline Brian Cade & 970.226 .9326 & BRD-FORT \\
\hline Sharon Campbell & 970.226 .9331 & BRD-FORT \\
\hline Daren Carlisle & 703.648 .6890 & WRD-HQ \\
\hline Jeanette Carpenter & 303.445 .2230 & BRD-FORT \\
\hline Jim Carter & 650.329 .4439 & WRD-WR \\
\hline Thomas Cecere & 703.648 .5551 & Geog \\
\hline Colleen Charles & 703.648 .4110 & BRD-HQ \\
\hline Brian Cole & 650.329 .4593 & USGS-WR \\
\hline Tony DeGange & 907.786 .3492 & BRD-AK \\
\hline Roger Denlinger & 360.993 .8904 & GD-CAVO \\
\hline Frank D'Erchia & 303.202 .4743 & $\mathrm{CRO}$ \\
\hline Ben Dietsch & 402.328 .4122 & WRD-NE \\
\hline Jeff Duda & 206.526 .6282 ext 233 & BRD-WFRC \\
\hline Eric Evenson & 609.771 .3904 & WRD-ER \\
\hline Jim Eychaner & 916.278 .9555 & WRD-WR \\
\hline Faith Fitzpatrick & 608.821 .3818 & WRD-ER \\
\hline Lorrie Flint & 916.278 .3223 & WRD-WR \\
\hline Jill Frankforter & 402.328 .4143 & WRD-NE \\
\hline Mary Freeman & 706.583 .0978 & BRD-PWRC \\
\hline
\end{tabular}




\begin{tabular}{|c|c|c|}
\hline Full name & Phone number & Affiliation \\
\hline Jonathan Friedman & 970.226 .9318 & BRD-FORT \\
\hline Janice Fulford & 228.688 .1501 & WRD-MS \\
\hline Guy Gelfenbaum & 650.329 .5483 & GD \\
\hline Allen Gellis & 443.498 .5581 & WRD-MD \\
\hline W. Reed Green & 501.228 .3607 & WRD \\
\hline Susan Greenlee & 605.594 .6011 & Geog-EDC \\
\hline Elly Griffin & 303.541 .3041 & WRD-HQ \\
\hline John Guthrie & 703.648 .4708 & Geog \\
\hline John Hamill & 928.556 .7364 & BRD-GCMRC \\
\hline Dave Hamilton & 970.226 .9383 & BRD-FORT \\
\hline Leanne Hanson & 970.226 .9262 & BRD-FORT \\
\hline Alex Haro & 413.863 .3806 & BRD-Conte Lab \\
\hline Judson Harvey & 703.648 .5876 & WRD-HQ \\
\hline James Hatten & 509.538.2299 ext 252 & BRD-CERC \\
\hline Lauren Hay & 303.236 .7279 & WRD-NRP \\
\hline Dave Heimann & 816.524 .3287 & WRD-MO \\
\hline Jay Hestbeck & 303.236.2730 ext 264 & $\mathrm{CRO}$ \\
\hline W. Brian Hughes & 770.903 .9162 & WRD-GA \\
\hline Elise Irwin & 334.844 .9190 & BRD \\
\hline Rob Jacobson & 573.876 .1844 & BRD-CERC \\
\hline John Jones & 703.648 .5543 & Geog-ER \\
\hline Sonya Jones & 770.409 .7705 & WRD \\
\hline Jason Kean & 303.273 .8608 & GD-Boulder \\
\hline Jonathan Kennen & 609.771 .3948 & WRD-NJ \\
\hline Jeff Kershner & 406.994 .5304 & BRD-NRMSC \\
\hline Julie Kiang & 703.648 .5364 & WRD \\
\hline Jack Kindinger & 727.803 .8747 ext 3018 & WRD-FL \\
\hline Anne Kinsinger & 206.220 .4578 & USGS-WR \\
\hline Paul Kinzel & 303.278 .7941 & WRD-NRP \\
\hline Jim Kircher & 303.236 .4882 ext 258 & WRD \\
\hline Noah Knowles & 650.329 .4476 & WRD-WR \\
\hline Chris Konrad & 206.343.4345 ext 375 & WRD-TNC \\
\hline Bill Labiosa & 650.329 .4279 & Geog-WR \\
\hline Lee Lamb & 970.226 .9314 & BRD-FORT \\
\hline Linda Leake & 608.781 .6269 & BRD \\
\hline Bill Lellis & 570.724 .3322 ext 222 & BRD-LSC \\
\hline Ben Letcher & 413.863 .3803 & BRD-Conte Lab \\
\hline Josh Linard & 303.236 .4882 ext 373 & WRD-CO \\
\hline Ken Lubinski & 608.781 .6297 & BRD-UMESC \\
\hline Lisa Lucas & 650.329 .4588 & WRD-HQ-CA \\
\hline Dennis Lynch & 503.251 .3265 & WRD-WR \\
\hline Jeff Mabe & 512.927 .3552 & WRD-TX \\
\hline Mike Mac & 573.876 .1900 & BRD-CERC \\
\hline Chris Magirl & 520.670 .6671 ext 267 & WRD-HQ \\
\hline Steve Markstrom & 303.236 .3330 & WRD \\
\hline Serena Mankiller & 928.556 .7094 & BRD-SWBSC \\
\hline Robert Mason & 703.648 .5305 & WRD-HQ \\
\hline Mark Mastin & 253.552 .1609 & WRD-WA \\
\hline
\end{tabular}




\begin{tabular}{|c|c|c|}
\hline Full name & Phone number & Affiliation \\
\hline Rich McDonald & 303.278 .7952 & WRD-NRP \\
\hline Ted Melis & 928.556 .7282 & BRD-GCMRC \\
\hline Bob Milhous & 970.226 .9322 & BRD-FORT \\
\hline Nancy Monsen & 650.329 .4337 & WRD-WR \\
\hline Scott Morlock & 317.290 .3333 ext 153 & WRD-IN \\
\hline John Moody & 303.541 .3011 & WRD-HQ \\
\hline Gordon Mueller & 303.445 .2218 & BRD-FORT \\
\hline Clint Muhlfeld & 406.888 .7926 & BRD \\
\hline Jonathan Nelson & 303.278 .7957 & WRD-NRP \\
\hline Elena Nilsen & 503.251 .3277 & WRD-OR \\
\hline Mike Nolan & 650.329 .4419 & WRD-WR \\
\hline Ken Odom & 334.395 .4140 & WRD-AL \\
\hline Waite Osterkamp & 520.670 .6821 ext 113 & WRD-HQ-AZ \\
\hline Andrea Ostroff & 703.648 .4070 & BRD-GAP \\
\hline Eben Paxton & 601.818 .8662 & BRD \\
\hline Charles Peters & 608.821 .3810 & WRD \\
\hline Kathy Peter & 208.387 .1316 & WRD-ID \\
\hline Jim Peterson & 706.542 .1166 & BRD-GA Coop \\
\hline Bruce Pugesek & 406.994.6144 & BRD-NRMSC \\
\hline Vivian Queija & 206.220 .4565 & Geog-WR \\
\hline Bob Renken & 954.377 .5922 & WRD-FL \\
\hline John Risley & 503.251 .3279 & WRD-OR \\
\hline Stewart Rounds & 503.251 .3280 & WRD-OR \\
\hline Rob Runkel & 303.236 .4882 ext 285 & WRD-CO \\
\hline Dave Russ & 703.648 .6660 & GD-ER \\
\hline Nathan Schaepe & 402.328 .4184 & WRD-NE \\
\hline Steve Schindler & 703.648 .5970 & GD-ER \\
\hline Travis Schmidt & 970.226 .9470 & GD-Post-doc \\
\hline Robin Schrock & 703.648 .4066 & BRD-HQ \\
\hline Mike Scott & 970.226 .9475 & BRD-FORT \\
\hline Pat Shafroth & 970.226 .9327 & BRD-FORT \\
\hline Mark Shasby & 970.226 .9398 & BRD-FORT \\
\hline Mark Sherfy & 701.253 .5504 & BRD-NPWRC \\
\hline Chris Sherwood & 508.457 .2269 & GD-ER \\
\hline Frank Shipley & 206.220 .4600 & BRD-WR \\
\hline Rip Shively & 541.273 .8689 & BRD-WFRC \\
\hline Allison Shipp & 541.880 .0040 & WR \\
\hline Francisco Simoes & 303.278 .7956 & WRD-NRP \\
\hline Peter Smith & 916.278 .3125 & WRD-CA \\
\hline Mark Sogge & 928.523 .7768 & BRD-SBSC \\
\hline Jeff Spooner & 573.308 .3526 & Geog-Rolla \\
\hline Ward Staubiz & 703.648 .5061 & WRD-HQ \\
\hline Jim Terrell & 970.226 .9416 & BRD-FORT \\
\hline Kathryn Thomas & 520.670 .5534 & BRD-SWBSC \\
\hline Janet Thompson & 650.329 .4364 & WRD-WR \\
\hline Lyman Thorsteinson & 206.526 .6282 ext 235 & BRD-WFRC \\
\hline Joan Thullen & 303.445 .2212 & BRD-FORT \\
\hline Christian Torgersen & 206.616.1874 & BRD-FRESC \\
\hline
\end{tabular}




\begin{tabular}{lll}
\hline \multicolumn{1}{c}{ Full name } & Phone number & \multicolumn{1}{c}{ Affiliation } \\
\hline Christine Turner & 303.236 .1561 & GD \\
Gary Turney & 253.552 .1626 & WRD-WA \\
Charles Van Riper & 520.626 .7027 & BRD-SBSC \\
Marijke vanHeeswijk & 253.552 .1625 & WRD-WA \\
Kris Verdin & 605.594 .6002 & Geog-EDC \\
Terry Waddle & 970.226 .9386 & BRD-FORT \\
Bob Webb & 520.670 .6671 ext 238 & WRD-HQ-AZ \\
Peter Weiskel & 508.490 .5026 & WRD-ER-MA \\
Emily Wheeler & 217.390 .6401 & BRD \\
Mark Wildhaber & 573.876 .1847 & BRD-CERC \\
Sam Williamson & 970.226 .9362 & BRD-FORT \\
Bob Winfree & 907.644 .3516 & NPS \\
Dave Wolock & 785.832 .3528 & WRD-KS \\
Molly Wood & 208.387 .1320 & WRD-ID \\
Nathan Wood & 360.993 .8951 & Geog-CAVO \\
Paul Young & 703.648 .5115 & Geog-ER \\
Ron Zelt & 402.328 .4140 & WRD-NE \\
Bob Zuellig & 970.226 .9419 & WRD-CO \\
\hline
\end{tabular}




\section{Appendix 5. Model Summary Sheets}

This appendix contains an alphabetical listing of the model summary sheets submitted by USGS employees. The models included here are currently being used or developed within USGS for river modeling applications. Blue text on each form indicates the information submitted for that model. Hotlinks are indicated by italicized text.

- $\quad$ BASINS (Better Assessment Science Integrating point \& Non-point Sources)

- $\quad$ BLTM (Branched Lagrangian Transport Model)

- $\quad$ BRANCH (Branch-Network Dynamic Flow Model)

- CAP (Culvert Analysis Program)

- CE-QUAL-W2

- CGAP (Channel Geometry Analysis Program)

- CSHHAD_CAL (Cross-Sectional Hydraulic Habitat Distribution Calculator)

- DAFLOW (Streamflow routing in upland channels or channel networks)

- DAMFLO.2

- DR3M (Distributed Routing Rainfall-Runoff Model)

- FASTMECH (Flow and Sediment Transport with Mechanical Evolution of Channels)

- FEQ (Full EQuations Model)

- FESWMS_FST2DH (Finite-Element Surface-Water Modeling System for two-dimensional flow in the horizontal plane)

- FourPT (Unsteady, one-dimensional, open-channel flow model)

- GENSCN (GENeration and analysis of model simulation SCeNarios)

- GLSNET (Regional hydrologic regression and NETwork analysis using Generalized Least Squares)

- GR (Graphing Application)

- GSFLOW (Ground- and Surface- Water Flow Model)

- HAT (Hydrologic Assessment Tool)

- HIT (Hydrologic Index Tool)

- HSPEXP (Expert System for Calibration of HSPF)

- HSPF (Hydrologic Simulation Program-FORTRAN)

- HYSEP (Hydrograph Separation Program)

- IFIM (Instream Flow Incremental Methodology)

- Knowledge Capturing and Analysis Tool for Floodplain Stakeholders

- LIAM (The Legal-Institutional Analysis Model)

- LOADEST (LOAD ESTimator)

- MD_SWMS (Multi-Dimensional Surface-Water Modeling System)

- MMS (Modular Modeling System)

- ModBranch (GW/SW Coupled Flow Model using MODFLOW and BRANCH)

- NSS (National Streamflow Statistics program)

- OTEQ (One-dimensional Transport with EQuilibrium chemistry)

- OTIS (One-dimensional Transport with Inflow and Storage)

- PeakFQ (Flood Frequency Analysis Based on Bulletin 17B)

- PHABSIM (Physical Habitat Simulation System)

- Predictive Models of Hydrologic Indicators

- PRMS (Precipitation-Runoff Modeling System)

- PRMS-LVDM-FMDS (Precipitation Runoff Modeling System, Landscape Vegetative Dynamics Models, Fish Metapopulation Dynamic Simulation)

- $\quad$ River 2D (River 2-Dimension)

- RAX (River-Aquifer Exchange Calculator)

- RMA2_SED2D

- ROMS / CSTM (Regional Ocean Modeling System / Community Sediment Transport Model)

- SAC (Slope-Area Computation Program) 
- SALMOD (Salmon Population Model)

- SalReP (Salmon Restoration Planning Model)

- SEDMOD (Mixed-Size Sediment Transport Model for Networks)

- SEM (Structural Equation Model)

- SI3D (Semi-Implicit, 3D Model for Estuarine Circulation)

- $\quad$ SIAM (Systems Impact Assessment Model)

- $\quad$ SNTEMP (Stream Network Temperature Model)

- SPARROW (SPAtially Referenced Regressions On Watershed Attributes)

- SToRM (System for Transport and River Modeling)

- StreamStats

- SWIFT2D (Surface-Water Integrated Flow and Transport 2D Model)

- $\quad$ SWSTAT (Surface Water Statistics)

- TRIMR2D (Transient Inundation Model for Rivers - 2 Dimensional)

- UNTRIM (Unstructured, Tidal, Residual, and Intertidal Mudflat)

- VPV (The Velocity Profile Viewer)

- WRRAT (Wood River Resource Analysis Tool)

- WSPRO (Water-Surface PROfile Computations) 
Model Name: BASINS (Better Assessment Science Integrating point \& Non-point Sources)

Is this one model or a suite of interrelated models? If a suite, list the name of each model:

Dimensions, list planes for 1D to Quasi-3D, and time step(s) for interrelated models:

1D Quasi-2D 2D Quasi-3D 3D Time

Color code all that apply:

1) Digital Conceptual Physical

2) Steady State Dynamic Conditions Statistical Simulation

3) Heuristic Decision-making Planning Operations

4) Cross-Section River Reach Sub-watershed Watershed State Region National

Platform Used (e.g., Windows, Mac, UNIX):

Purpose: A multipurpose environmental analysis system designed for regional, state, and local agencies that perform watershed and water quality-based studies.

Inputs:

Outputs:

Output Format Accessible by: Microsoft Windows Office Environment $\quad$ Yes or No ESRI ArcGIS Suite Yes or No

Spatial Extent of Solution and Minimum Mapping Unit or Cell Dimensions:

Developer/Affiliation:

Current Users (If many, list groups e.g., X District, U.S. Army Corps of Engineers):

Applied at what geographic locations, if many locations, provide broad example. Also, what publications/court cases/Environmental Impact Statements used this model?

Examples:

Supported at what location and by whom. Also, is support current?

(contact name, e-mail, phone number, mailing address)

Public Use?

Off-the-shelf availability?

Does the model reside with the Developer or User?

URL to access model: basins@epa.gov

http://www.epa.gov/waterscience/BASINS/

License Fees:

Other important model characteristics and model linkages: 
Model Name: BLTM (Branched Lagrangian Transport Model)

Is this one model or a suite of interrelated models? If a suite, list the name of each model:

Dimensions, list planes for 1D to Quasi-3D, and time step(s) for interrelated models:

1D Quasi-2D 2D Quasi-3D 3D Time

Color code all that apply:

1) Digital Conceptual Physical

2) Steady State Dynamic Conditions Statistical Simulation

3) Heuristic Decision-making Planning Operations

4) Cross-Section River Reach Sub-watershed Watershed State Region National

Platform Used (e.g., Windows, Mac, UNIX):

Purpose: Solves the 1D convective-diffusion equation with reaction kinetics with any number of interacting constituents through a system of 1D channels.

Inputs:

Outputs:

Output Format Accessible by: Microsoft Windows Office Environment $\quad$ Yes or No ESRI ArcGIS Suite Yes or No

Spatial Extent of Solution and Minimum Mapping Unit or Cell Dimensions:

Developer/Affiliation:

Current Users (If many, list groups e.g., X District, U.S. Army Corps of Engineers):

Applied at what geographic locations, if many locations, provide broad example. Also, what publications/court cases/Environmental Impact Statements used this model?

Examples:

Supported at what location and by whom. Also, is support current?

(contact name, e-mail, phone number, mailing address)

Public Use?

Off-the-shelf availability?

Does the model reside with the Developer or User?

URL to access model: h2osoft@usgs.gov

http://water.usgs.gov/software/BLTM/

License Fees:

Other important model characteristics and model linkages: 
Model Name: BRANCH (Branch-Network Dynamic Flow Model)

Is this one model or a suite of interrelated models? If a suite, list the name of each model:

Dimensions, list planes for 1D to Quasi-3D, and time step(s) for interrelated models:

1D Quasi-2D 2D Quasi-3D 3D Time

Color code all that apply:

1) Digital Conceptual Physical

2) Steady State Dynamic Conditions Statistical Simulation

3) Heuristic Decision-making Planning Operations

4) Cross-Section River Reach Sub-watershed Watershed State Region National

Platform Used (e.g., Windows, Mac, UNIX):

Purpose: Simulates steady or unsteady flow in a single open-channel reach (branch) or throughout a system of branches (network) connected in a dendritic or looped pattern.

Inputs:

Outputs:

Output Format Accessible by: Microsoft Windows Office Environment $\quad$ Yes or No ESRI ArcGIS Suite Yes or No

Spatial Extent of Solution and Minimum Mapping Unit or Cell Dimensions:

Developer/Affiliation:

Current Users (If many, list groups e.g., X District, U.S. Army Corps of Engineers):

Applied at what geographic locations, if many locations, provide broad example. Also, what publications/court cases/Environmental Impact Statements used this model?

Examples:

Supported at what location and by whom. Also, is support current?

(contact name, e-mail, phone number, mailing address)

Public Use?

Off-the-shelf availability?

Does the model reside with the Developer or User?

URL to access model: h2osoft@usgs.gov

http://water.usgs.gov/software/branch.html

License Fees:

Other important model characteristics and model linkages: 
Model Name: CAP (Culvert Analysis Program)

Is this one model or a suite of interrelated models? If a suite, list the name of each model:

Dimensions, list planes for 1D to Quasi-3D, and time step(s) for interrelated models:

1D Quasi-2D 2D Quasi-3D 3D Time

Color code all that apply:

1) Digital Conceptual Physical

2) Steady State Dynamic Conditions Statistical Simulation

3) Heuristic Decision-making Planning Operations

4) Cross-Section River Reach Sub-watershed Watershed State Region National

Platform Used (e.g., Windows, Mac, UNIX):

Purpose: Uses standardized procedures for computing flow through culverts

Inputs:

Outputs:

Output Format Accessible by: Microsoft Windows Office Environment $\quad$ Yes or No

ESRI ArcGIS Suite Yes or No

Spatial Extent of Solution and Minimum Mapping Unit or Cell Dimensions:

Developer/Affiliation:

Current Users (If many, list groups e.g., X District, U.S. Army Corps of Engineers):

Applied at what geographic locations, if many locations, provide broad example. Also, what publications/court cases/Environmental Impact Statements used this model?

Examples:

Supported at what location and by whom. Also, is support current?

(contact name, e-mail, phone number, mailing address)

Public Use?

Off-the-shelf availability?

Does the model reside with the Developer or User?

URL to access model: h2osoft@usgs.gov

http://water.usgs.gov/software/Cap.html

License Fees:

Other important model characteristics and model linkages: 
Model Name: CE-QUAL-W2

Is this one model or a suite of interrelated models? If a suite, list the name of each model:

One model

Dimensions, list planes for 1D to Quasi-3D, and time step(s) for interrelated models:

1D Quasi-2D 2D Quasi-3D 3D Time

Color code all that apply:

1) Digital Conceptual Physical

2) Steady State Dynamic Conditions Statistical Simulation

3) Heuristic Deterministic Decision-making Planning Operations

4) Cross-Section River Reach Sub-watershed Watershed State Region National

Platform Used (e.g., Windows, Mac, UNIX): any

Purpose: mechanistic branched network model of flow, water temperature, and water quality for rivers, lakes, reservoirs, and estuaries

Inputs: boundary conditions (stage or flow, temperature, water quality), meteorological data (wind speed, direction, air temp, dew point, cloud cover, solar radiation), bathymetry, roughness, various kinetic rate parameters, etc.

Outputs: flow, velocities, stage, water temperature, water quality parameters, fluxes, etc.

Output Format Accessible by: Microsoft Windows Office Environment Yes or No ESRI ArcGIS Suite Yes or No

Spatial Extent of Solution and Minimum Mapping Unit or Cell Dimensions: river reach

Developer/Affiliation: U.S. Army Corps of Engineers \& Portland State University

Current Users: a cast of thousands around the world

Applied at what geographic locations, if many locations, provide broad example. Also, what publications/court cases/Environmental Impact Statements used this model?

Examples: See user manual. Over 500+ applications around the globe.

Supported at what location and by whom. Also, is support current?

(contact name, e-mail, phone number, mailing address)

Scott Wells, scott@cecs.pdx.edu

Public Use? Yes

Off-the-shelf availability? Yes

Does the model reside with the Developer or User? User

URL to access model: http://www.cee.pdx.edu/w2/

License Fees: None 
Other important model characteristics and model linkages: CE-QUAL-W2 is a two-dimensional (longitudinal, vertical) model from the U.S. Army Corps of Engineers. CE-QUAL-W2 is a physically based mechanistic model that simulates gravity- and wind-driven flow through a network of interconnected river channels or reservoir reaches by using channel geometry and slope, bottom friction, wind shear, density effects, and upstream/downstream flow or water-level data. Algorithms to calculate the effect of hydraulic structures such as weirs, pumps, and spillways are included. Horizontal and vertical velocities, flow, and stage are simulated.

Water temperature is modeled in CE-QUAL-W2 by using a detailed expression of the energy budget of the water body. The model includes algorithms to dynamically calculate the effects of both topographic and vegetative shading. Using latitude, longitude, time of day, and the water body's orientation, the model determines at each time step the presence or absence of a topographic or vegetative shadow on the water surface, the length of any shadow, and the degree to which that shadow shields the water body from solar radiation. Model inputs include meteorological data, topographic shading angles, tree-top elevations, distance to the vegetation, and solar-reduction factors associated with the riparian canopy that vary by location.

In addition to modeling flow and water temperature, CE-QUAL-W2 can simulate many water-quality constituents, including conservative and nonconservative tracers, bacteria, different forms of nitrogen (nitrate and ammonia) and phosphorus, multiple phytoplankton and epiphyton groups, dissolved oxygen, multiple suspendedsediment groups, and dissolved and particulate organic matter, to name a few. CE-QUAL-W2 has open source code, good documentation, and a large user community. In addition, it has a long history of successful application to a wide range of lake, reservoir, estuary, and river systems.

Model Name: CGAP (Channel Geometry Analysis Program)

Is this one model or a suite of interrelated models? If a suite, list the name of each model:

Dimensions, list planes for 1D to Quasi-3D, and time step(s) for interrelated models:

1D Quasi-2D 2D Quasi-3D 3D Time

Color code all that apply:

1) Digital Conceptual Physical

2) Steady State Dynamic Conditions Statistical Simulation

3) Heuristic Decision-making Planning Operations

4) Cross-Section River Reach Sub-watershed Watershed State Region National

Platform Used (e.g., Windows, Mac, UNIX):

Purpose: Analysis, interpretation, and quantification of physical properties of an open-channel reach defined by cross sections.

Inputs:

Outputs:

Output Format Accessible by: Microsoft Windows Office Environment $\quad$ Yes or No ESRI ArcGIS Suite Yes or No

Spatial Extent of Solution and Minimum Mapping Unit or Cell Dimensions:

Developer/Affiliation:

Current Users (If many, list groups e.g., X District, U.S. Army Corps of Engineers):

Applied at what geographic locations, if many locations, provide broad example. Also, what publications/court 
cases/Environmental Impact Statements used this model?

Examples:

Supported at what location and by whom. Also, is support current?

(contact name, e-mail, phone number, mailing address)

Public Use?

Off-the-shelf availability?

Does the model reside with the Developer or User?

URL to access model: h2osoft@usgs.gov

http://water.usgs.gov/software/cgap.html

License Fees:

Other important model characteristics and model linkages:

Model Name: CSHHAD_CAL (Cross-Sectional Hydraulic Habitat Distribution Calculator)

Is this one model or a suite of interrelated models? If a suite, list the name of each model:

Not a suite

Dimensions, list planes for 1D to Quasi-3D, and time step(s) for interrelated models:

Quasi-2D (W and D, not streamwise); but integrates multi-temporal data for same cross section location.

Color code all that apply:

1) Digital

2) Dynamic Conditions Statistical

3) Heuristic Decision-making Planning Operations

4) Cross-Section River Reach

Platform Used (e.g., Windows, Mac, UNIX): Windows

Purpose:

The calculator is intended for use by individual(s) using the cross-sectional data of wetted channel for characterizing the distribution of streamflow depth, velocity, discharge, and other metrics derived from cross-sectional information. The calculator enables users to achieve consistent and rapid streamflow cross-sectional data analysis; therefore saves time for other project tasks.

Inputs:

Input is data routinely recorded on the U.S. Geological Survey Form 9-275F or other equivalent forms (e.g., nonUSGS measurements) during streamflow cross-sectional measurement: the distance of each sampling vertical from a reference point, water depth, point velocity(ies), horizontal streamline-angle coefficient, left and right edge of water, and left and right edges of stream interruptions (e.g., sandbars, islands, and piers)

Outputs:

Area- or Width-weighted cumulative frequency distribution of parameters of aquatic habitat, distribution of prespecified habitat classes throughout each cross section. Includes descriptive statistics of each metric distribution and 
for summarizing central tendancy and variability of the frequency distribution among multiple sets of cross-sectional measurements.

Output Format Accessible by: Microsoft Windows Office Environment Yes ESRI ArcGIS Suite No

Spatial Extent of Solution and Minimum Mapping Unit or Cell Dimensions:

Variable, depending on lateral density of input cross-sectional measurements

Developer/Affiliation:

Developed for the Lower Platte River Cumulative Impact Study, by USGS-Nebr. WSC, in cooperation with the Lower Platte Source Natural Resources District.

Current Users (If many, list groups e.g., X District, U.S. Army Corps of Engineers):

Presently used only by USGS Nebr. WSC. Once approved for external release, plans for use in geomorphic study of Niobrara River in cooperation with Nebraska Game \& Parks Commission.

Applied at what geographic locations, if many locations, provide broad example. Also, what publications/court cases/Environmental Impact Statements used this model?

Several gaging sites along the lower Platte River, Nebraska;

results relate to USFWS consultations for continued bank stabilization and levees constructed by USACE; results were used in USGS SIR, now in final tech/specialist review.

Supported at what location and by whom. Also, is support current?

(contact name, e-mail, phone number, mailing address)

No formal support or updates planned presently; developed during completion of reimbursable project. Contact/ resource is Daniel Ginting, USGS Nebr. WSC, dginting@usgs.gov, 402-328-4121

Public Use? Planned (once approved, will be released to the public)

Off-the-shelf availability? Not yet. Will be released with OFR that is in preparation now

Does the model reside with the Developer or User? Developer

License Fees: None

Other important model characteristics and model linkages: The program is designed for Excel 2003 using a graphical user interface (GUI) written with Excel Visual Basic for Applications. Simple installation: All intermediate and final results of calculations were written in the same worksheet; this calculator sheet is copied into same workbook where input data are located. Graphical representation of results is included as output. The intermediate values may be important for use with other applications or analyses. Beside the already wide familiarity with the Excel program, the GUI makes using the program intuitive and easy.

Program input format could be readily modified to accept output from the forthcoming module of the USGS NWIS (ADAPS) system where cross-sectional details will soon be archivable in an electronic relational data system. 
Model Name: DAFLOW (Streamflow routing in upland channels or channel networks)

Is this one model or a suite of interrelated models? If a suite, list the name of each model:

Dimensions, list planes for 1D to Quasi-3D, and time step(s) for interrelated models:

1D Quasi-2D 2D Quasi-3D 3D Time

Color code all that apply:

1) Digital Conceptual Physical

2) Steady State Dynamic Conditions Statistical Simulation

3) Heuristic Decision-making Planning Operations

4) Cross-Section River Reach Sub-watershed Watershed State Region National

Platform Used (e.g., Windows, Mac, UNIX):

Purpose: Streamflow routing using the diffusion analogy form of the flow equations in conjunction with a Lagrangian solution scheme.

Inputs:

Outputs:

Output Format Accessible by: Microsoft Windows Office Environment $\quad$ Yes or No ESRI ArcGIS Suite Yes or No

Spatial Extent of Solution and Minimum Mapping Unit or Cell Dimensions:

Developer/Affiliation:

Current Users (If many, list groups e.g., X District, U.S. Army Corps of Engineers):

Applied at what geographic locations, if many locations, provide broad example. Also, what publications/court cases/Environmental Impact Statements used this model?

Examples:

Supported at what location and by whom. Also, is support current?

(contact name, e-mail, phone number, mailing address)

Public Use?

Off-the-shelf availability?

Does the model reside with the Developer or User?

URL to access model: h2osoft@usgs.gov

http://water.usgs.gov/software/daflow.html

License Fees:

Other important model characteristics and model linkages: 
Model Name: DAMFLO.2

Is this one model or a suite of interrelated models? If a suite, list the name of each model:

Dimensions, list planes for 1D to Quasi-3D, and time step(s) for interrelated models:

1D Quasi-2D 2D Quasi-3D 3D Time

Color code all that apply:

1) Digital Conceptual Physical

2) Steady State Dynamic Conditions Statistical Simulation

3) Heuristic Decision-making Planning Operations

4) Cross-Section River Reach Sub-watershed Watershed State Region National

Platform Used (e.g., Windows, Mac, UNIX):

Purpose: Computes flow through dam structures using hydraulic equations that describe flow through sluice and Tainter gates, crest gates, lock gates, spillways, locks, pumps, and siphons.

Inputs:

Outputs:

Output Format Accessible by: Microsoft Windows Office Environment $\quad$ Yes or No ESRI ArcGIS Suite Yes or No

Spatial Extent of Solution and Minimum Mapping Unit or Cell Dimensions:

Developer/Affiliation:

Current Users (If many, list groups e.g., X District, U.S. Army Corps of Engineers):

Applied at what geographic locations, if many locations, provide broad example. Also, what publications/court cases/Environmental Impact Statements used this model?

Examples:

Supported at what location and by whom. Also, is support current?

(contact name, e-mail, phone number, mailing address)

Toby Feaster, USGS(tfeaster@usgs.gov)

Public Use?

Off-the-shelf availability?

Does the model reside with the Developer or User?

URL to access model: http://pubs.usgs.gov/of/2003/ofr03473/

License Fees:

Other important model characteristics and model linkages: 
Model Name: DR3M (Distributed Routing Rainfall-Runoff Model)

Is this one model or a suite of interrelated models? If a suite, list the name of each model:

Dimensions, list planes for 1D to Quasi-3D, and time step(s) for interrelated models:

1D Quasi-2D 2D Quasi-3D 3D Time

Color code all that apply:

1) Digital Conceptual Physical

2) Steady State Dynamic Conditions Statistical Simulation

3) Heuristic Decision-making Planning Operations

4) Cross-Section River Reach Sub-watershed Watershed State Region National

Platform Used (e.g., Windows, Mac, UNIX):

Purpose: Watershed model for routing storm runoff through a branched system of pipes and (or) natural channels using rainfall as input.

Inputs:

Outputs:

Output Format Accessible by: Microsoft Windows Office Environment $\quad$ Yes or No ESRI ArcGIS Suite Yes or No

Spatial Extent of Solution and Minimum Mapping Unit or Cell Dimensions:

Developer/Affiliation:

Current Users (If many, list groups e.g., X District, U.S. Army Corps of Engineers):

Applied at what geographic locations, if many locations, provide broad example. Also, what publications/court cases/Environmental Impact Statements used this model?

Examples:

Supported at what location and by whom. Also, is support current?

(contact name, e-mail, phone number, mailing address)

Public Use?

Off-the-shelf availability?

Does the model reside with the Developer or User?

URL to access model: h2osoft@usgs.gov

http://water.usgs.gov/software/DR3M/

License Fees:

Other important model characteristics and model linkages: 
Model Name: FASTMECH (Flow and Sediment Transport with Mechanical Evolution of Channels)

Is this one model or a suite of interrelated models? If a suite, list the name of each model:

Dimensions, list planes for 1D to Quasi-3D, and time step(s) for interrelated models:

$$
\text { 1D Quasi-2D 2D Quasi-3D 3D Time }
$$

Color code all that apply:

1) Digital Conceptual Physical

2) Steady State Dynamic Conditions Statistical Simulation

3) Heuristic Decision-making Planning Operations

4) Cross-Section River Reach Sub-watershed Watershed State Region National

Platform Used (e.g., Windows, Mac, UNIX):

Purpose: 2D vertical average and quasi-3D general steady-state flow.

Inputs:

Outputs:

Output Format Accessible by: Microsoft Windows Office Environment $\quad$ Yes or No ESRI ArcGIS Suite Yes or No

Spatial Extent of Solution and Minimum Mapping Unit or Cell Dimensions:

Developer/Affiliation:

Current Users (If many, list groups e.g., X District, U.S. Army Corps of Engineers):

Applied at what geographic locations, if many locations, provide broad example. Also, what publications/court cases/Environmental Impact Statements used this model?

Examples:

Supported at what location and by whom. Also, is support current?

(contact name, e-mail, phone number, mailing address)

Jonathan Nelson, USGS (jmn@usgs.gov)

Richard McDonald, USGS (rmcd@usgs.gov)

Public Use?

Off-the-shelf availability?

Does the model reside with the Developer or User?

URL to access model: http://wwwbrr.cr.usgs.gov/projects/GEOMORPH_Lab/project-FaSTMECH.html

License Fees:

Other important model characteristics and model linkages: also see MD_SWMS 
Model Name: FEQ (Full EQuations Model)

Is this one model or a suite of interrelated models? If a suite, list the name of each model:

Dimensions, list planes for 1D to Quasi-3D, and time step(s) for interrelated models:

1D Quasi-2D 2D Quasi-3D 3D Time

Color code all that apply:

1) Digital Conceptual Physical

2) Steady State Dynamic Conditions Statistical Simulation

3) Heuristic Decision-making Planning Operations

4) Cross-Section River Reach Sub-watershed Watershed State Region National

Platform Used (e.g., Windows, Mac, UNIX):

Purpose: Simulate steady or unsteady flow in a single open-channel reach (branch) or throughout a system of branches (network) connected in a dendritic or looped pattern.

Inputs:

Outputs:

Output Format Accessible by: Microsoft Windows Office Environment $\quad$ Yes or No ESRI ArcGIS Suite Yes or No

Spatial Extent of Solution and Minimum Mapping Unit or Cell Dimensions:

Developer/Affiliation:

Current Users (If many, list groups e.g., X District, U.S. Army Corps of Engineers):

Applied at what geographic locations, if many locations, provide broad example. Also, what publications/court cases/Environmental Impact Statements used this model?

Examples:

Supported at what location and by whom. Also, is support current? (contact name, e-mail, phone number, mailing address)

Audrey Ishii, USGS (alishii@usgs.gov)

Public Use?

Off-the-shelf availability?

Does the model reside with the Developer or User?

URL to access model: http://il.water.usgs.gov/proj/feq

License Fees:

Other important model characteristics and model linkages: 
Model Name: FESWMS_FST2DH (Finite-Element Surface-Water Modeling System for two-dimensional flow in the horizontal plane)

Is this one model or a suite of interrelated models? If a suite, list the name of each model:

One model

Dimensions, list planes for 1D to Quasi-3D, and time step(s) for interrelated models:

1D Quasi-2D 2D Quasi-3D 3D Time

Color code all that apply:

1) Digital Conceptual Physical

2) Steady State Dynamic Conditions Statistical Simulation

3) Heuristic Decision-making Planning Operations

4) Cross-Section River Reach Sub-watershed Watershed State Region National

Platform Used (e.g., Windows, Mac, UNIX): Windows

Purpose: Determining flooding extent for FEMA Letter of Map Revision.

Inputs: Discharge, downstream wse, eddy viscosity

Outputs: Velocity, depths, wse

Output Format Accessible by: Microsoft Windows Office Environment Yes or No ESRI ArcGIS Suite Yes or No

Spatial Extent of Solution and Minimum Mapping Unit or Cell Dimensions:

Reach model, cell dimensions variable

Developer/Affiliation: Federal Highway Administration

Current Users (If many, list groups e.g., X District, U.S. Army Corps of Engineers):

Applied at what geographic locations, if many locations, provide broad example. Also, what publications/court cases/Environmental Impact Statements used this model?

Examples: Sni-A-Bar Creek, west-central Missouri

Rydlund, P.H., Jr., Otero-Benítez, W. and Heimann, D.C., 2008, Hydraulic analyses of Sni-A-Bar Creek and selected tributaries at Grain Valley, Jackson County, Missouri: U.S. Geological Survey Scientific Investigations Report 20085051, 57 p. plus films.

Supported at what location and by whom. Also, is support current? (contact name, e-mail, phone number, mailing address)

Federal Highway Administration

Public Use? Yes

Off-the-shelf availability? Yes

Does the model reside with the Developer or User? Developer 
URL to access model: http://water.usgs.gov/software/FESWMS-2DH/

License Fees: None

Other important model characteristics and model linkages: Used within the SMS pre-, post-processing software

Model Name: FourPT (Unsteady, one-dimensional, open-channel flow model)

Is this one model or a suite of interrelated models? If a suite, list the name of each model:

Dimensions, list planes for 1D to Quasi-3D, and time step(s) for interrelated models:

1D Quasi-2D 2D Quasi-3D 3D Time

Color code all that apply:

1) Digital Conceptual Physical

2) Steady State Dynamic Conditions Statistical Simulation

3) Heuristic Decision-making Planning Operations

4) Cross-Section River Reach Sub-watershed Watershed State Region National

Platform Used (e.g., Windows, Mac, UNIX):

Purpose: Simulates steady or unsteady flow in a single open-channel reach (branch) or throughout a system of branches (network) connected in a dendritic or looped pattern.

Inputs:

Outputs:

Output Format Accessible by: Microsoft Windows Office Environment $\quad$ Yes or No ESRI ArcGIS Suite Yes or No

Spatial Extent of Solution and Minimum Mapping Unit or Cell Dimensions:

Developer/Affiliation:

Current Users (If many, list groups e.g., X District, U.S. Army Corps of Engineers):

Applied at what geographic locations, if many locations, provide broad example. Also, what publications/court cases/Environmental Impact Statements used this model?

Examples:

Supported at what location and by whom. Also, is support current? (contact name, e-mail, phone number, mailing address)

Public Use?

Off-the-shelf availability?

Does the model reside with the Developer or User?

URL to access model: h2osoft@usgs.gov 
http://water.usgs.gov/software/FourPt.html

License Fees:

Other important model characteristics and model linkages:

Model Name: GENSCN (GENeration and analysis of model simulation SCeNarios)

Is this one model or a suite of interrelated models? If a suite, list the name of each model:

Dimensions, list planes for 1D to Quasi-3D, and time step(s) for interrelated models:

1D Quasi-2D 2D Quasi-3D 3D Time

Color code all that apply:

1) Digital Conceptual Physical

2) Steady State Dynamic Conditions Statistical Simulation

3) Heuristic Decision-making Planning Operations

4) Cross-Section River Reach Sub-watershed Watershed State Region National

Platform Used (e.g., Windows, Mac, UNIX):

Purpose: A tool for generating and analyzing model simulations from the HSFP watershed model.

Inputs:

Outputs:

Output Format Accessible by: Microsoft Windows Office Environment $\quad$ Yes or No ESRI ArcGIS Suite Yes or No

Spatial Extent of Solution and Minimum Mapping Unit or Cell Dimensions:

Developer/Affiliation:

Current Users (If many, list groups e.g., X District, U.S. Army Corps of Engineers):

Applied at what geographic locations, if many locations, provide broad example. Also, what publications/court cases/Environmental Impact Statements used this model?

Examples:

Supported at what location and by whom. Also, is support current?

(contact name, e-mail, phone number, mailing address)

Public Use?

Off-the-shelf availability?

Does the model reside with the Developer or User?

URL to access model: h2osoft@usgs.gov

http://water.usgs.gov/software/genscn.html 
License Fees:

Other important model characteristics and model linkages: also see HSPF

Model Name: GLSNET (Regional hydrologic regression and NETwork analysis using Generalized Least Squares)

Is this one model or a suite of interrelated models? If a suite, list the name of each model:

Dimensions, list planes for 1D to Quasi-3D, and time step(s) for interrelated models:

1D Quasi-2D 2D Quasi-3D 3D Time

Color code all that apply:

1) Digital Conceptual Physical

2) Steady State Dynamic Conditions Statistical Simulation

3) Heuristic Decision-making Planning Operations

4) Cross-Section River Reach Sub-watershed Watershed State Region National

Platform Used (e.g., Windows, Mac, UNIX):

Purpose: Uses residuals techniques to estimate a regional regression equation to predict flow characteristics at ungaged sites.

Inputs:

Outputs:

Output Format Accessible by: Microsoft Windows Office Environment $\quad$ Yes or No ESRI ArcGIS Suite Yes or No

Spatial Extent of Solution and Minimum Mapping Unit or Cell Dimensions:

Developer/Affiliation:

Current Users (If many, list groups e.g., X District, U.S. Army Corps of Engineers):

Applied at what geographic locations, if many locations, provide broad example. Also, what publications/court cases/Environmental Impact Statements used this model?

Examples:

Supported at what location and by whom. Also, is support current?

(contact name, e-mail, phone number, mailing address)

Public Use?

Off-the-shelf availability?

Does the model reside with the Developer or User?

URL to access model: h2osoft@usgs.gov

http://water.usgs.gov/software/GLSNet/ 
License Fees:

Other important model characteristics and model linkages:

Model Name: GR (Graphing Application)

Is this one model or a suite of interrelated models? If a suite, list the name of each model:

Dimensions, list planes for 1D to Quasi-3D, and time step(s) for interrelated models:

1D Quasi-2D 2D Quasi-3D 3D Time

Color code all that apply:

1) Digital Conceptual Physical

2) Steady State Dynamic Conditions Statistical Simulation

3) Heuristic Decision-making Planning Operations

4) Cross-Section River Reach Sub-watershed Watershed State Region National

Platform Used (e.g., Windows, Mac, UNIX):

Purpose: A comprehensive editing and visualization solution for multidimensional data. Also be used to display or animate vector data, particle paths, or two-dimensional (2D) data fields. GR is often used with time series data, but it will work with any data that describes $\mathrm{Y}$ as a function of $\mathrm{X}$.

Inputs:

Outputs:

Output Format Accessible by: Microsoft Windows Office Environment $\quad$ Yes or No ESRI ArcGIS Suite Yes or No

Spatial Extent of Solution and Minimum Mapping Unit or Cell Dimensions:

Developer/Affiliation:

Current Users (If many, list groups e.g., X District, U.S. Army Corps of Engineers):

Applied at what geographic locations, if many locations, provide broad example. Also, what publications/court cases/Environmental Impact Statements used this model?

Examples:

Supported at what location and by whom. Also, is support current?

(contact name, e-mail, phone number, mailing address)

John Donovan, USGS (jmd@usgs.gov)

Public Use?

Off-the-shelf availability?

Does the model reside with the Developer or User? 
URL to access model: http://ca.water.usgs.gov/program/sfbay/gr/

http://www.ecst.csuchico.edu/ jmd/gr/

License Fees:

Other important model characteristics and model linkages:

Model Name: GSFLOW (Ground- and Surface-Water Flow Model)

Is this one model or a suite of interrelated models? If a suite, list the name of each model:

PRMS and MODFLOW-2005

Dimensions, list planes for 1D to Quasi-3D, and time step(s) for interrelated models:

1D Quasi-2D 2D Quasi-3D 3D Time one day (mean daily values)

Color code all that apply:

1) Digital Conceptual Physical Numerical

2) Steady State Dynamic Conditions Statistical Simulation

3) Heuristic Decision-making Planning Operations

4) Cross-Section River Reach Sub-watershed Watershed State Region National

Platform Used (e.g., Windows, Mac, UNIX): Windows and Linux

Purpose: GSFLOW was developed to simulate coupled groundwater/surface-water flow in one or more watersheds by simultaneously simulating flow across the land surface and within subsurface saturated and unsaturated materials.

Inputs: Measured (station data) temperature, precipitation, solar radiation (optional). Land surface characterization, hydraulic conductivity, and storage coefficients.

Outputs: Many states and fluxes which describe the water balance on the land surface, unsaturated and saturated zones, rivers, and lakes.

Output Format Accessible by: Microsoft Windows Office Environment Yes or No ESRI ArcGIS Suite Yes or No

Spatial Extent of Solution and Minimum Mapping Unit or Cell Dimensions:

Resolution is $10 \mathrm{~m}^{2}$ to $10 \mathrm{~s}$ of $\mathrm{km}^{2}$. Scale is $10 \mathrm{~s}$ of $\mathrm{km}^{2}$ to $10,000 \mathrm{~s} \mathrm{~km}^{2}$.

Developer/Affiliation: Markstrom, Niswonger, Regan, Barlow, and Prudic (USGS)

Current Users (If many, list groups e.g., X District, U.S. Army Corps of Engineers): Wisconsin, Nevada, California, and Pennsylvania Water Science Centers (in beta testing phase)

Applied at what geographic locations, if many locations, provide broad example. Also, what publications/court cases/Environmental Impact Statements used this model?

Examples: It has been applied/tested in snow-melt basin in the Sierra Nevada (California), lake dominated basin in northern Wisconsin, and carstic system in central Pennsylvania.

Supported at what location and by whom. Also, is support current?

(contact name, e-mail, phone number, mailing address)

Will be supported by developers in 2008 
Public Use? Yes

Off-the-shelf availability? More or less

Does the model reside with the Developer or User? User

URL to access model: http://water.usgs.gov/nrp/gwsoftware/gsflow/gsflow.html

License Fees: Public domain

Other important model characteristics and model linkages:

Model Name: HAT (Hydrologic Assessment Tool)

Is this one model or a suite of interrelated models? If a suite, list the name of each model:

One modeling tool.

Dimensions, list planes for 1D to Quasi-3D, and time step(s) for interrelated models:

1D Quasi-2D 2D Quasi-3D 3D Time Step: None

Color code all that apply:

1) Digital Conceptual Physical

2) Steady State Dynamic Conditions Statistical Simulation

3) Heuristic Decision-making Planning Operations

4) Cross-Section River Reach Sub-watershed Watershed State Region National

Platform Used (e.g., Windows, Mac, UNIX): Windows

Purpose: Setting standards for environmental flows and performing water management alternative analyses

Inputs: Daily flow, peak flow, drainage area, alternative flow scenarios

Outputs: 171 hydrologic indices for comparison of baseline and alternative flow scenarios

Output Format Accessible by: Microsoft Windows Office Environment Yes or No

ESRI ArcGIS Suite Yes or No

Spatial Extent of Solution and Minimum Mapping Unit or Cell Dimensions: NA

Developer/Affiliation: USGS

Current Users (If many, list groups e.g., X District, U.S. Army Corps of Engineers):

States of New Jersey, Missouri, Texas and Pennsylvania

Applied at what geographic locations, if many locations, provide broad example. Also, what publications/court cases/Environmental Impact Statements used this model?

Examples: Rivers and streams located in states listed above.

Supported at what location and by whom. Also, is support current? No

(contact name, e-mail, phone number, mailing address)

USGS-FORT, Sharon Campbell, campbells@usgs.gov, 970-226-9331 
Public Use? Yes

Off-the-shelf availability? Yes

Does the model reside with the Developer or User? User, download from USGS FORT website.

URL to access model: http://www.fort.usgs.gov/Products/Software/

License Fees: None - public domain

Other important model characteristics and model linkages: Jim Henriksen, USGS FORT has retired. Support is limited to model documentation and user guides available from FORT website.

Model Name: HIT (Hydrologic Index Tool)

Is this one model or a suite of interrelated models? If a suite, list the name of each model:

One modeling tool

Dimensions, list planes for 1D to Quasi-3D, and time step(s) for interrelated models:

1D Quasi-2D 2D Quasi-3D 3D Time Step: None

Color code all that apply:

1) Digital Conceptual Physical

2) Steady State Dynamic Conditions Statistical Simulation

3) Heuristic Decision-making Planning Operations

4) Cross-Section River Reach Sub-watershed Watershed State Region National

Platform Used (e.g., Windows, Mac, UNIX): Windows

Purpose: Computing hydrologic indices for a river reach (one gage)

Inputs: Daily flow, peak flow, drainage area

Outputs: 171 hydrologic indices

Output Format Accessible by: Microsoft Windows Office Environment Yes or No ESRI ArcGIS Suite Yes or No

Spatial Extent of Solution and Minimum Mapping Unit or Cell Dimensions: NA

Developer/Affiliation: USGS FORT/Colorado State University

Current Users (If many, list groups e.g., X District, U.S. Army Corps of Engineers):

States of New Jersey, Missouri, Texas, Pennsylvania, USGS (Various)

Applied at what geographic locations, if many locations, provide broad example. Also, what publications/court cases/Environmental Impact Statements used this model?

Examples: River and streams in states listed above and nationally, at most USGS gages.

Supported at what location and by whom. Also, is support current? NO 
(contact name, e-mail, phone number, mailing address)

USGS-FORT, Sharon Campbell, campbells@usgs.gov, 970-226-9331

Public Use? Yes

Off-the-shelf availability? Yes

Does the model reside with the Developer or User? User, download from USGS FORT website

URL to access model: http://www.fort.usgs.gov/Products/Software/

License Fees: None - public domain

Other important model characteristics and model linkages: This modeling tool is used for stream classification by the user. Jim Henriksen, USGS FORT has retired. Support for this model is limited to model documentation and use available on the FORT website.

Model Name: HSPEXP (Expert System for Calibration of HSPF)

Is this one model or a suite of interrelated models? If a suite, list the name of each model:

Dimensions, list planes for 1D to Quasi-3D, and time step(s) for interrelated models:

1D Quasi-2D 2D Quasi-3D 3D Time

Color code all that apply:

1) Digital Conceptual Physical

2) Steady State Dynamic Conditions Statistical Simulation

3) Heuristic Decision-making Planning Operations

4) Cross-Section River Reach Sub-watershed Watershed State Region National

Platform Used (e.g., Windows, Mac, UNIX):

Purpose: Interactively edit the User Control Input (UCI) file for HSPF, simulate HSPF, produce output plots, compared to observed values, compute error statistics, and provide user with expert advice on which parameters should be changed up or down to improve the calibration.

Inputs:

Outputs:

Output Format Accessible by: Microsoft Windows Office Environment $\quad$ Yes or No ESRI ArcGIS Suite Yes or No

Spatial Extent of Solution and Minimum Mapping Unit or Cell Dimensions:

Developer/Affiliation:

Current Users (If many, list groups e.g., X District, U.S. Army Corps of Engineers):

Applied at what geographic locations, if many locations, provide broad example. Also, what publications/court cases/Environmental Impact Statements used this model? 
Examples:

Supported at what location and by whom. Also, is support current?

(contact name, e-mail, phone number, mailing address)

Public Use?

Off-the-shelf availability?

Does the model reside with the Developer or User?

URL to access model: h2osoft@usgs.gov

http://water.usgs.gov/software/HSPexp/

License Fees:

Other important model characteristics and model linkages:

Model Name: HSPF (Hydrologic Simulation Program-FORTRAN)

Is this one model or a suite of interrelated models? If a suite, list the name of each model:

One model

Dimensions, list planes for 1D to Quasi-3D, and time step(s) for interrelated models:

1D Quasi-2D 2D Quasi-3D 3D Time

Color code all that apply:

1) Digital Conceptual Physical

2) Steady State Dynamic Conditions Statistical Simulation

3) Heuristic Decision-making Planning Operations

4) Cross-Section River Reach Sub-watershed Watershed State Region National

Platform Used (e.g., Windows, Mac, UNIX):

Windows

Purpose: Determining effects of impoundments and land cover on streamflows.

Inputs: Topography, land cover, precipitation, potential evapotranspiration, temperature

Outputs: Streamflow time series

Output Format Accessible by: Microsoft Windows Office Environment Yes or No ESRI ArcGIS Suite Yes or No

Spatial Extent of Solution and Minimum Mapping Unit or Cell Dimensions:

Watershed, sub-watershed reaches

Developer/Affiliation: USGS, EPA

Current Users (If many, list groups e.g., X District, U.S. Army Corps of Engineers):

Applied at what geographic locations, if many locations, provide broad example. Also, what publications/court 
cases/Environmental Impact Statements used this model?

Examples: Upper Osage River Basin, Missouri and Kansas

Heimann, D.C., Licher, S.S. and Schalk, G.K., 2007, Effects of Impoundments and Land-

Cover Changes on Streamflows and Selected Fish Habitat in the upper Osage River Basin, Missouri and Kansas:

U.S. Geological Survey, Scientific Investigations Report 2007-5175, 96 p.

Supported at what location and by whom. Also, is support current?

(contact name, e-mail, phone number, mailing address) EPA, USGS

Public Use? Yes

Off-the-shelf availability? Yes

Does the model reside with the Developer or User? Developer

URL to access model: http://water.usgs.gov/cgi-bin/man_wrdapp?hspf

http://www.epa.gov/waterscience/basins/

License Fees: None

Other important model characteristics and model linkages: Used within the BASINS system of models and utilities http://www.epa.gov/waterscience/basins/

Model Name: HYSEP (Hydrograph Separation Program)

Is this one model or a suite of interrelated models? If a suite, list the name of each model:

Dimensions, list planes for 1D to Quasi-3D, and time step(s) for interrelated models:

1D Quasi-2D 2D Quasi-3D 3D Time

Color code all that apply:

1) Digital Conceptual Physical

2) Steady State Dynamic Conditions Statistical Simulation

3) Heuristic Decision-making Planning Operations

4) Cross-Section River Reach Sub-watershed Watershed State Region National

Platform Used (e.g., Windows, Mac, UNIX):

Purpose: Performs hydrograph separation, estimating the ground

Inputs:

Outputs:

Output Format Accessible by: Microsoft Windows Office Environment $\quad$ Yes or No ESRI ArcGIS Suite Yes or No

Spatial Extent of Solution and Minimum Mapping Unit or Cell Dimensions:

Developer/Affiliation: 
Current Users (If many, list groups e.g., X District, U.S. Army Corps of Engineers):

Applied at what geographic locations, if many locations, provide broad example. Also, what publications/court cases/Environmental Impact Statements used this model?

Examples:

Supported at what location and by whom. Also, is support current? (contact name, e-mail, phone number, mailing address)

Public Use?

Off-the-shelf availability?

Does the model reside with the Developer or User?

URL to access model: h2osoft@usgs.gov

http://water.usgs.gov/software/HYSEP

License Fees:

Other important model characteristics and model linkages:

Model Name: IFIM (Instream Flow Incremental Methodology)

Is this one model or a suite of interrelated models? If a suite, list the name of each model:

This model is a framework for addressing instream flow decisions. It can incorporate any institutional, physical, or biological conceptual or numerical models that address IFIM component processes.

Dimensions, list planes for 1D to Quasi-3D, and time step(s) for interrelated models:

1D Quasi-2D 2D Quasi-3D 3D Time Can be any or all of these

Color code all that apply:

1) Digital Conceptual Physical

2) Steady State Dynamic Conditions Statistical Simulation Decision Support

3) Heuristic Decision-making Planning Operations

4) Cross-Section River Reach Sub-watershed Watershed State Region National

Platform Used (e.g., Windows, Mac, UNIX): n/a

Purpose: To provide an organized approach to multi-agency, multi-discipline, multi-stakeholder resource allocation problems related to instream flow management.

Inputs: Willingness of participants to talk, need to reach a conclusion, legal or institutional forcing function, eg. permit processes, specific data requirements for selected component models

Outputs: Vary by decision making setting

Output Format Accessible by: n/a Microsoft Windows Office Environment Yes or No ESRI ArcGIS Suite Yes or No

Spatial Extent of Solution and Minimum Mapping Unit or Cell Dimensions: Defined by the users 
Developer/Affiliation: Instream Flow Group, USFWS

Current Users (If many, list groups e.g., X District, U.S. Army Corps of Engineers):

A full list of users has not been compiled, but includes state and federal agencies and others outside the United States. However, experience suggests users tend to use the easy parts and avoid the hard parts until they find that won't work.

Applied at what geographic locations, if many locations, provide broad example. Also, what publications/court cases/ Environmental Impact Statements used this model used?

World wide

Supported at what location and by whom. Also, is support current?

(contact name, e-mail, phone number, mailing address)

USGS Contact: Ken Bovee boveek@usgs.gov

Public Use? Yes

Off-the-shelf availability? Yes

Does the model reside with the Developer or User? Users

URL to access model: http://www.fort.usgs.gov/Products/Software/IFIM//

License Fees: None

Other important model characteristics and model linkages: Some models developed by the Instream Flow Group that can be used as part of IFIM are available at http://www.fort.usgs.gov/Products/Software/. They include PHABSIM - Physical Habitat Simulation System, SNTEMP - Stream Network Temperature Model, LIAM - Legal and Institutional Analysis Model. Specific implementations of IFIM as decision support systems are also available from the same web site, for example: the Delaware River Decision Support System (DRDSS),

http://www.fort.usgs.gov/Products/Software/DRDSS/.

Model Name: Knowledge Capturing and Analysis Tool for Floodplain Stakeholders

Is this one model or a suite of interrelated models? If a suite, list the name of each model:

Two versions of the same model, developed by different stakeholder groups.

Dimensions, list planes for 1D to Quasi-3D, and time step(s) for interrelated models:

1D Quasi-2D 2D Quasi-3D 3D Time step $=1$ year.

Color code all that apply:

1) Digital Conceptual Physical

2) Steady State Dynamic Conditions Statistical Simulation

3) Heuristic Decision-making Planning Operations

4) Cross-Section River Reach Sub-watershed Watershed State Region National

Platform Used (e.g., Windows, Mac, UNIX): Windows running STELLA

Purpose: To assist river stakeholders in understanding the factors controlling land ownership and allocation in the Mississippi River floodplain and to allow them to forecast future conditions under different management alternatives.

Inputs: Stakeholder mental models, gut feelings and assumptions 
Outputs: Land use change over time and abstracted translation of land use into floodplain functionality parameters

Output Format Accessible by: Microsoft Windows Office Environment Yes or No ESRI ArcGIS Suite Yes or No

Spatial Extent of Solution and Minimum Mapping Unit or Cell Dimensions: NA

Developer/Affiliation: Multiple Scientists, University of Illinois and USGS

Current Users (If many, list groups e.g., X District, U.S. Army Corps of Engineers): Model is not currently being used.

Applied at what geographic locations, if many locations, provide broad example. Upper Mississippi River. Also, what publications/court cases/Environmental Impact Statements used this model?

Examples:

Supported at what location and by whom. Emily Wheeler, University of Illinois at Urbana-Champaign, 1604 S. Vine Street, Urbana, IL 61801, 217.390.6401, erwheele@uiuc.edu

Also, is support current? Yes

Public Use? Yes, the model is available for public use. The models are locked for editing

Off-the-shelf availability? Yes

Does the model reside with the Developer or User? Developer

URL to access model: https://netfiles.uiuc.edu/erwheele/shared/Great\%20Rivers\%20Models/

License Fees: No. There is a free version of STELLA available for running models at: http://www.iseesystems.com/

Other important model characteristics and model linkages: The importance of these scoping level conceptual models rests in their ability to capture stakeholder viewpoints and assumptions -i.e. the outputs are not meant to be rigorously validated and quantitative but rather to reflect back to the user what might happen if this collective conception of reality is indeed realistic. There is potential for validation of assumptions and conversion of this type of model into a synthetic hub for more sophisticated models of each component (i.e. fish models, hydrological models, economic models etc.).

Model Name: LIAM (The Legal-Institutional Analysis Model)

Is this one model or a suite of interrelated models? If a suite, list the name of each model:

One model

Dimensions, list planes for 1D to Quasi-3D, and time step(s) for interrelated models:

1D Quasi-2D 2D Quasi-3D 3D Time

Color code all that apply:

1) Digital Conceptual Physical

2) Steady State Dynamic Conditions Statistical Simulation

3) Heuristic Decision-making Planning Operations

4) Cross-Section River Reach Sub-watershed Watershed State Region National 
Platform Used (e.g., Windows, Mac, UNIX): Windows

Purpose: To assess the legal and institutional setting of a specific decision process and to use that information to design a negotiation strategy

Inputs: Users answer a series of questions about each stakeholder regarding that stakeholder's likely motivations and behavior in a specific negotiation

Outputs: A "role map" that places each stakeholder in one of four quadrants, based on their preference for type of process (continuum from "brokered" to "arbitrated") and type of outcome (continuum from "status quo" to "change.")

Output Format Accessible by: Microsoft Windows Office Environment Yes or No ESRI ArcGIS Suite Yes or No

Spatial Extent of Solution and Minimum Mapping Unit or Cell Dimensions:

Developer/Affiliation: Lee Lamb, USGS; Leah J. Wilds, University of Nevada-Reno; Jonathan G. Taylor, USGS (but all were USFWS-Instream Flow Group at time of development)

Current Users (If many, list groups e.g., X District, U.S. Army Corps of Engineers):

We serve the software on the FORT website and do not know who uses it. We use it on request in a workshop setting to help stakeholders understand the likely dynamics of upcoming negotiations.

Applied at what geographic locations, if many locations, provide broad example. Also, what publications/court cases/Environmental Impact Statements used this model?

Examples:

Terror River, AK; various Wyoming locations for grizzly bear management issue; Idaho-Montana FERC relicensing issue, others.

Burkardt, N., and P.D. Ponds. 2006. Using role analysis to plan for stakeholder involvement: a comparison of three workshops. Wildlife Society Bulletin 34(5): 1306-1313.

Lamb, B.L., J.G. Taylor, N.Burkardt, and P.D. Ponds. 1998. A policy model to initiate environmental negotiations: three hydropower workshops. Human Dimensions of Wildlife 3(4): 1-17.

Supported at what location and by whom. Also, is support current?

(contact name, e-mail, phone number, mailing address)

Supported at USGS-FORT, served on website. Contact for model is Nina Burkardt, burkardtn@usgs.gov; 970-

226-9275. Address: FORT, 2150-C Centre Avenue, Fort Collins, CO, 80526. Model is in need of update/reprogramming and more user-friendly options.

Public Use? Yes

Off-the-shelf availability? Yes, can download from FORT website

Does the model reside with the Developer or User? Developer, but users can download.

URL to access model: http://www.fort.usgs.gov/Products/Software/

License Fees: None 
Other important model characteristics and model linkages: Model was developed as part of the Instream Flow Incremental Methodology to help decision makers and other stakeholders understand legal-institutional setting, and how the use of information derived from IFIM and other studies could be used in complex decision environments.

Model Name: LOADEST (LOAD ESTimator)

Is this one model or a suite of interrelated models? If a suite, list the name of each model:

Dimensions, list planes for 1D to Quasi-3D, and time step(s) for interrelated models:

1D Quasi-2D 2D Quasi-3D 3D Time

Color code all that apply:

1) Digital Conceptual Physical

2) Steady State Dynamic Conditions Statistical Simulation

3) Heuristic Decision-making Planning Operations

4) Cross-Section River Reach Sub-watershed Watershed State Region National

Platform Used (e.g., Windows, Mac, UNIX):

Purpose: Estimates constituent loads in streams and rivers over a user-specified time interval.

Inputs:

Outputs:

Output Format Accessible by: Microsoft Windows Office Environment $\quad$ Yes or No ESRI ArcGIS Suite Yes or No

Spatial Extent of Solution and Minimum Mapping Unit or Cell Dimensions:

Developer/Affiliation:

Current Users (If many, list groups e.g., X District, U.S. Army Corps of Engineers):

Applied at what geographic locations, if many locations, provide broad example. Also, what publications/court cases/Environmental Impact Statements used this model?

Examples:

Supported at what location and by whom. Also, is support current?

(contact name, e-mail, phone number, mailing address)

Public Use?

Off-the-shelf availability?

Does the model reside with the Developer or User?

URL to access model: h2osoft@usgs.gov

http://water.usgs.gov/software/loadest/ 
License Fees:

Other important model characteristics and model linkages:

Model Name: MD_SWMS (Multi-Dimensional Surface-Water Modeling System)

Is this one model or a suite of interrelated models? If a suite, list the name of each model:

Suite of interrelated models including FASTMECH, STORM, H2KE, RMHAB

Dimensions, list planes for 1D to Quasi-3D, and time step(s) for interrelated models:

1D Quasi-2D 2D Quasi-3D 3D Time

2d, 2d w/time step, quasi-3d, quasi-3d with time step

Color code all that apply:

1) Digital Conceptual Physical

2) Steady State Dynamic Conditions Statistical Simulation

3) Heuristic Decision-making Planning Operations

4) Cross-Section River Reach Sub-watershed Watershed State Region National

Platform Used (e.g., Windows, Mac, UNIX): Windows

Purpose: Modeling flow, sediment transport, bed evolution, habitat, etc

Inputs: Topography, roughness in various forms, discharge or hydrograph, measured data for water surface elevation, velocity, etc

Outputs: All hydrodynamic variables, sediment flux, bed erosion/deposition rates, morphologic change, habitat parameters, all calibration/verification parameters

Output Format Accessible by: Microsoft Windows Office Environment $\quad$ Yes ESRI ArcGIS Suite No

Spatial Extent of Solution and Minimum Mapping Unit or Cell Dimensions: No limitations

Developer/Affiliation: Rich McDonald, Jonathan Nelson, Francisco Simoes, Yasuyuki Shimizu, Hiroshi

Takebayashi, Craig Addley

Current Users (If many, list groups e.g., X District, U.S. Army Corps of Engineers):

Many, including USGS, USFWS, USFS, many universities and other NGOs

Applied at what geographic locations, if many locations, provide broad example. Also, what publications/court cases/Environmental Impact Statements used this model?

Examples: Many: Colorado, Green, Kootenai, Platte, Columbia, Trinity, Sacramento, Merced, Kern, Copper, Knik, Tanana, White, Ohio, Missouri, Yellowstone, Red River Vietnam, other small rivers and streams; many pubs, NRDA court case, some EIS inclusions

Supported at what location and by whom. Also, is support current?

(contact name, e-mail, phone number, mailing address)

USGS Geomorphology and Sediment Transport Laboratory

4620 Technology Drive, Suite 400

Golden, CO 80403 
Current support, Rich McDonald (rmcd@usgs.gov, 303-278-7952), Jonathan Nelson (jmn@usgs.gov, 303-278-7957)

Public Use? Open source, public domain (both interface and all models)

Off-the-shelf availability? Download at GSTL website

Does the model reside with the Developer or User? Both

URL to access model: http://wwwbrr.cr.usgs.gov/gstl/

License Fees: None

Other important model characteristics and model linkages:

Model Name: MMS (Modular Modeling System)

Is this one model or a suite of interrelated models? If a suite, list the name of each model:

Dimensions, list planes for 1D to Quasi-3D, and time step(s) for interrelated models:

1D Quasi-2D 2D Quasi-3D 3D Time

Color code all that apply:

1) Digital Conceptual Physical

2) Steady State Dynamic Conditions Statistical Simulation

3) Heuristic Decision-making Planning Operations

4) Cross-Section River Reach Sub-watershed Watershed State Region National

Platform Used (e.g., Windows, Mac, UNIX):

Purpose: Modular Modeling System (MMS) is a toolbox for water- and environmental-resources modeling and management. Selected models and modules in MMS are: PRMS, GSFLOW, WEBMOD, TOPMODEL, Hydro-17 (NWS snowmelt), Sacramento Model (NWS), Snowmelt Runoff Model (SRM) (ARS), and ENNS Model (modified HBV, Austria).

Inputs:

Outputs:

Output Format Accessible by: Microsoft Windows Office Environment $\quad$ Yes or No ESRI ArcGIS Suite Yes or No

Spatial Extent of Solution and Minimum Mapping Unit or Cell Dimensions:

Developer/Affiliation:

Current Users (If many, list groups e.g., X District, U.S. Army Corps of Engineers):

Applied at what geographic locations, if many locations, provide broad example. Also, what publications/court cases/Environmental Impact Statements used this model?

Examples:

Supported at what location and by whom. Also, is support current?

(contact name, e-mail, phone number, mailing address) 
Lauren Hay, USGS (lhay@usgs.gov)

Public Use?

Off-the-shelf availability?

Does the model reside with the Developer or User?

URL to access model: http://wwwbrr.cr.usgs.gov/projects/SW_MoWS/index.shtml

License Fees:

Other important model characteristics and model linkages:

Model Name: ModBranch (GW/SW Coupled Flow Model using MODFLOW and BRANCH)

Is this one model or a suite of interrelated models? If a suite, list the name of each model:

Dimensions, list planes for 1D to Quasi-3D, and time step(s) for interrelated models:

1D Quasi-2D 2D Quasi-3D 3D Time

Color code all that apply:

1) Digital Conceptual Physical

2) Steady State Dynamic Conditions Statistical Simulation

3) Heuristic Decision-making Planning Operations

4) Cross-Section River Reach Sub-watershed Watershed State Region National

Platform Used (e.g., Windows, Mac, UNIX):

Purpose: Simulates surface- and ground-water interactions, steady or unsteady flow in a single open-channel reach (branch) or throughout a system of branches (network) connected in a dendritic or looped pattern by solving the onedimensional equations of continuity and momentum for the river flow.

Inputs:

Outputs:

Output Format Accessible by: Microsoft Windows Office Environment $\quad$ Yes or No ESRI ArcGIS Suite Yes or No

Spatial Extent of Solution and Minimum Mapping Unit or Cell Dimensions:

Developer/Affiliation:

Current Users (If many, list groups e.g., X District, U.S. Army Corps of Engineers):

Applied at what geographic locations, if many locations, provide broad example. Also, what publications/court cases/Environmental Impact Statements used this model?

Examples:

Supported at what location and by whom. Also, is support current? 
(contact name, e-mail, phone number, mailing address)

Public Use?

Off-the-shelf availability?

Does the model reside with the Developer or User?

URL to access model: h2osoft@usgs.gov

http://water.usgs.gov/software/MODBRNCH/

License Fees:

Other important model characteristics and model linkages:

Model Name: NSS (National Streamflow Statistics program)

Is this one model or a suite of interrelated models? If a suite, list the name of each model:

Dimensions, list planes for 1D to Quasi-3D, and time step(s) for interrelated models:

1D Quasi-2D 2D Quasi-3D 3D Time

Color code all that apply:

1) Digital Conceptual Physical

2) Steady State Dynamic Conditions Statistical Simulation

3) Heuristic Decision-making Planning Operations

4) Cross-Section River Reach Sub-watershed Watershed State Region National

Platform Used (e.g., Windows, Mac, UNIX):

Purpose: Provides simple methods of estimating streamflow statistics in the United States.

Inputs:

Outputs:

Output Format Accessible by: Microsoft Windows Office Environment $\quad$ Yes or No ESRI ArcGIS Suite Yes or No

Spatial Extent of Solution and Minimum Mapping Unit or Cell Dimensions:

Developer/Affiliation:

Current Users (If many, list groups e.g., X District, U.S. Army Corps of Engineers):

Applied at what geographic locations, if many locations, provide broad example. Also, what publications/court cases/Environmental Impact Statements used this model?

Examples:

Supported at what location and by whom. Also, is support current?

(contact name, e-mail, phone number, mailing address) 
Public Use?

Off-the-shelf availability?

Does the model reside with the Developer or User?

URL to access model: h2osoft@usgs.gov

http://water.usgs.gov/software/NSS/

License Fees:

Other important model characteristics and model linkages:

Model Name: OTEQ (One-dimensional Transport with EQuilibrium chemistry)

Is this one model or a suite of interrelated models? If a suite, list the name of each model:

Dimensions, list planes for 1D to Quasi-3D, and time step(s) for interrelated models:

1D Quasi-2D 2D Quasi-3D 3D Time

Color code all that apply:

1) Digital Conceptual Physical

2) Steady State Dynamic Conditions Statistical Simulation

3) Heuristic Decision-making Planning Operations

4) Cross-Section River Reach Sub-watershed Watershed State Region National

Platform Used (e.g., Windows, Mac, UNIX): Unix (Solaris), Linux

Purpose: Simulate fate and transport of metals subject to equilibruium chemistry

Inputs: parameter estimates, upstream boundary condition, streamflow

Outputs: simulated concentrations of stream and storage zone solute concentration

Output Format Accessible by: Microsoft Windows Office Environment Yes or No

ESRI ArcGIS Suite Yes or No

(output is in the form of simple ascii flat files)

Spatial Extent of Solution and Minimum Mapping Unit or Cell Dimensions:

Developer/Affiliation: Rob Runkel USGS CO WSC (runkel@usgs.gov)

Current Users (If many, list groups e.g., X District, U.S. Army Corps of Engineers): Internal USGS research; public version is forthcoming

Applied at what geographic locations, if many locations, provide broad example. Also, what publications/court cases/Environmental Impact Statements used this model?

Examples: streams and small rivers in Colorado and Utah

Supported at what location and by whom. Also, is support current? Yes

Rob Runkel USGS CO WSC (runkel@usgs.gov) 
Public Use? Planned for late FY08

Off-the-shelf availability? Planned for late FY08

Does the model reside with the Developer or User? User

URL to access model: http://co.water.usgs.gov/oteq/

License Fees: None

Other important model characteristics and model linkages:

Model Name: OTIS (One-dimensional Transport with Inflow and Storage)

Is this one model or a suite of interrelated models? If a suite, list the name of each model:

Dimensions, list planes for 1D to Quasi-3D, and time step(s) for interrelated models:

1D Quasi-2D 2D Quasi-3D 3D Time

Color code all that apply:

1) Digital Conceptual Physical

2) Steady State Dynamic Conditions Statistical Simulation

3) Heuristic Decision-making Planning Operations

4) Cross-Section River Reach Sub-watershed Watershed State Region National

Platform Used (e.g., Windows, Mac, UNIX): DOS window, Unix, Linux

Purpose: Use observed stream tracer data to estimate parameters describing "Transient Storage"

Inputs: initial parameter estimates, timeseries of observed tracer data

Outputs: simulated concentrations of stream and storage zone tracer concentration

Output Format Accessible by: Microsoft Windows Office Environment Yes or No

ESRI ArcGIS Suite Yes or No

(output is in the form of simple ascii flat files)

Spatial Extent of Solution and Minimum Mapping Unit or Cell Dimensions:

Developer/Affiliation: Rob Runkel USGS CO WSC (runkel@usgs.gov)

Current Users (If many, list groups e.g., X District, U.S. Army Corps of Engineers): numerous. Primarily stream ecologists working outside of the USGS.

Applied at what geographic locations, if many locations, provide broad example. Also, what publications/court cases/Environmental Impact Statements used this model?

Examples: see (outdated) list at http://co.water.usgs.gov/otis/documentation/applications/index.html

Supported at what location and by whom. Also, is support current? Yes

Rob Runkel USGS CO WSC (runkel@usgs.gov)

Public Use? Yes 
Off-the-shelf availability? Yes

Does the model reside with the Developer or User? User

URL to access model: http://co.water.usgs.gov/otis/

License Fees: none

Other important model characteristics and model linkages:

Model Name: PeakFQ (Flood Frequency Analysis Based on Bulletin 17B)

Is this one model or a suite of interrelated models? If a suite, list the name of each model:

Dimensions, list planes for 1D to Quasi-3D, and time step(s) for interrelated models:

1D Quasi-2D 2D Quasi-3D 3D Time

Color code all that apply:

1) Digital Conceptual Physical

2) Steady State Dynamic Conditions Statistical Simulation

3) Heuristic Decision-making Planning Operations

4) Cross-Section River Reach Sub-watershed Watershed State Region National

Platform Used (e.g., Windows, Mac, UNIX):

Purpose: Provides estimates of instantaneous annual-maximum peak flows for a range of recurrence intervals.

Inputs:

Outputs:

Output Format Accessible by: Microsoft Windows Office Environment $\quad$ Yes or No ESRI ArcGIS Suite Yes or No

Spatial Extent of Solution and Minimum Mapping Unit or Cell Dimensions:

Developer/Affiliation:

Current Users (If many, list groups e.g., X District, U.S. Army Corps of Engineers):

Applied at what geographic locations, if many locations, provide broad example. Also, what publications/court cases/Environmental Impact Statements used this model?

Examples:

Supported at what location and by whom. Also, is support current?

(contact name, e-mail, phone number, mailing address)

Public Use?

Off-the-shelf availability? 
Does the model reside with the Developer or User?

URL to access model: h2osoft@usgs.gov

http://water.usgs.gov/software/PeakFQ/

License Fees:

Other important model characteristics and model linkages:

Model Name: PHABSIM (Physical Habitat Simulation System)

Is this one model or a suite of interrelated models? If a suite, list the name of each model:

The model is a collection of programs

Dimensions, list planes for 1D to Quasi-3D, and time step(s) for interrelated models:

1D Quasi-2D 2D Quasi-3D 3D Time

Color code all that apply:

1) Digital Conceptual Physical

2) Steady State Dynamic Conditions Statistical Simulation

3) Heuristic Decision-making Planning Operations

4) Cross-Section River Reach Sub-watershed Watershed State Region National

Platform Used (e.g., Windows, Mac, UNIX):

There are two versions 1) a windows version and 2) a version that uses dos commands.

Purpose: To develop a set of relations between streamflow and habitat for selected species of aquatic organisms

Inputs: Cross-sectional, substrate, and velocity data, habitat suitability criteria for target aquatic organisms

Outputs: The set of habitat versus streamflow relations

Output Format Accessible by: Microsoft Windows Office Environment Yes or No ESRI ArcGIS Suite Yes or No

Spatial Extent of Solution and Minimum Mapping Unit or Cell Dimensions:

Defined by the user, generally confined to river segments or samples from related river segments

Developer/Affiliation: Instream Flow Group, USFWS

Current Users (If many, list groups e.g., X District, U.S. Army Corps of Engineers):

A full list of users has not been compiled, but includes state and federal agencies and others outside the United States. There is current substantial use in Spain and Italy. Organizations in Norway, France and the UK have implemented their own versions.

Applied at what geographic locations, if many locations, provide broad example. Also, what publications/court cases/Environmental Impact Statements used this model?

Examples: Rachel Spence and Phil Hickley. 2000. The use of PHABSIM in the management of water resources and fisheries in England and Wales. Ecological Engineering 16 pp 152-158.

Many others can be found using a Google search with 'Physical Habitat Simulation System PHABSIM. 
Supported at what location and by whom. Also, is support current?

(contact name, e-mail, phone number, mailing address)

DOS version is unsupported at this time. Windows version is supported on a time-available basis. Contact Terry Waddle: waddlet@usgs.gov.

Public Use? Yes

Off-the-shelf availability? Yes

Does the model reside with the Developer or User? Users, who download it

URL to access model: http://www.fort.usgs.gov/Products/Software/PHABSIM/

License Fees: None

Other important model characteristics and model linkages: The model is used as part of the Instream Flow Incremental Methodology (IFIM). IFIM provides a framework for temporal and spatial integration of model results in an instream flow decision making context.

Model Name: Predictive Models of Hydrologic Indicators

Is this one model or a suite of interrelated models? If a suite, list the name of each model:

ONE model for each indicator

Dimensions, list planes for 1D to Quasi-3D, and time step(s) for interrelated models:

1D Quasi-2D 2D Quasi-3D 3D Time

Color code all that apply:

1) Digital Conceptual Physical

2) Steady State Dynamic Conditions Statistical Simulation

3) Heuristic Decision-making Planning Operations

4) Cross-Section River Reach Sub-watershed Watershed State Region National

Platform Used (e.g., Windows, Mac, UNIX): Any

Purpose: Predict expected natural flow regime (i.e., defined by aggregation of hydrologic indictors) for river segments. Assessments of hydrologic alteration are then possible for segments with sufficient period of flow data.

Inputs: Set of GIS-derived predictor variables (e.g., climate, topography, soils) calculated for basins above river segments for which predictions are desired.

Outputs: The expected value (or distribution of expectations from internal bootstrapped predictions) for a given hydrologic indicator for each segment.

Output Format Accessible by: Microsoft Windows Office Environment $\quad$ Yes or No ESRI ArcGIS Suite Yes or No

Spatial Extent of Solution and Minimum Mapping Unit or Cell Dimensions: Point estimate for each segment for which a basin has been delineated and predictor variables calculated.

Developer/Affiliation: NAWQA, Ecological National Synthesis and Hydrologic Systems Teams 
Current Users (If many, list groups e.g., X District, U.S. Army Corps of Engineers): Internal

Applied at what geographic locations, if many locations, provide broad example. Also, what publications/court cases/Environmental Impact Statements used this model?

Examples: Not yet released to public_-bureau approval of report forthcoming.

Supported at what location and by whom. Also, is support current?

(Daren Carlisle,dcarlisle@usgs.gov, MS 413 Reston, VA)

Public Use? Not at present

Off-the-shelf availability? No

Does the model reside with the Developer or User? Yes

URL to access model: N/A

License Fees: N/A

Other important model characteristics and model linkages: ABSTRACT of report that describes models:

Predicting the Natural Flow Regime: Models for Assessing Hydrological Alteration in Streams

Daren M. Carlisle ${ }^{1}$

James Falcone ${ }^{1}$

David M. Wolock ${ }^{2}$

Michael R. Meador ${ }^{1}$

Richard H. Norris ${ }^{3}$

${ }^{1}$ National Water-Quality Assessment Program, U.S. Geological Survey, 413 National Center, Reston, VA 20192 USA

${ }^{2}$ National Water-Quality Assessment Program, U.S. Geological Survey, Lawrence, KS USA

${ }^{3}$ Cooperative Research Centre for Freshwater Ecology, University of Canberra, Canberra, Australian Capital

Territory, Australia

Ecological assessments of streams are incomplete without understanding whether the natural flow regime is intact. Assessing hydrologic alteration (i.e., condition) requires that we quantify the attributes of the flow regime that would be expected in the absence of anthropogenic disturbance. Our objective was to evaluate whether indicators of the natural flow regime could be predicted at regional and national spatial scales using geospatial data. We first selected 1,272 gaged river basins throughout the contiguous U.S. where the hydrologic regimes were either least disturbed or near pristine. Using the period of record for these sites, we calculated 13 hydrologic indicators of magnitude, frequency, duration, timing, and rate of change. We used a robust modeling approach to evaluate the precision with which each indicator could be predicted with a single national and several regional models. We compared the precision of predictive models to that of "null" models, where expected values of each indicator were constant across hydrologic regions and ecoregions. A single national predictive model produced the most precise estimates for most indicators. Error rates ranged from $15-40 \%$, but were $<=25 \%$ for most indicators. We selected three gaged, nonreference sites to illustrate how predictive models could be used to assess site-specific hydrologic condition. These examples show how the model accurately estimates pre-disturbance hydrology and how reservoir construction and urbanization can affect hydrologic condition. 
Model Name: Precipitation-Runoff Modeling System (PRMS)

Is this one model or a suite of interrelated models? If a suite, list the name of each model:

One model

Dimensions, list planes for 1D to Quasi-3D, and time step(s) for interrelated models:

1D Quasi-2D 2D Quasi-3D 3D Time Time step is either one day (mean daily values) or unit values

Color code all that apply:

1) Digital Conceptual Physical

2) Steady State Dynamic Conditions Statistical Simulation

3) Heuristic Decision-making Planning Operations

4) Cross-Section River Reach Sub-watershed Watershed State Region National

Platform Used (e.g., Windows, Mac, UNIX): Windows and Linux

Purpose: The purpose of PRMS is: (1) simulation of land surface hydrologic processes, including evapotranspiration, runoff, infiltration, and interflow, by balancing energy and mass budgets of the plant canopy, snowpack, and soil zone; (2) simulation of hydrologic water budgets, at the watershed scale, with temporal scale ranging from minutes to centuries; (3) integration with models used for natural resource management or other scientific disciplines; and (4) has a modular design that allows for selection of alternative hydrologic process algorithms among existing or easily added modules.

Inputs: Measured (station data) temperature, precipitation, and optionally solar radiation

Outputs: Many states and fluxes which describe the water balance on the land surface and rivers

Output Format Accessible by: Microsoft Windows Office Environment $\quad$ Yes or No ESRI ArcGIS Suite Yes or No

Spatial Extent of Solution and Minimum Mapping Unit or Cell Dimensions: Resolution is $1 \mathrm{~km}^{2}$ to $100 \mathrm{~s}$ of $\mathrm{km}^{2}$. Scale is $10 \mathrm{~s}$ of $\mathrm{km}^{2}$ to $10,000 \mathrm{sm}^{2}$.

Developer/Affiliation: George Leavesley, et al (USGS)

Current Users (If many, list groups e.g., X District, U.S. Army Corps of Engineers): Many Water Science Centers, many universities, several international groups

Applied at what geographic locations, if many locations, provide broad example. Also, what publications/court cases/Environmental Impact Statements used this model?

Examples: It has been applied in many of the snow-melt basins in the western U.S. Other (rain and eastern U.S.) basins too. See http://wwwbrr.cr.usgs.gov/projects/SW_MoWS/software/oui_and_mms_s/prmsBib.shtml

for bibliography.

Supported at what location and by whom. Also, is support current?

(contact name, e-mail, phone number, mailing address)

Supported by USGS "Modeling of Watershed Systems" project:

http://wwwbrr.cr.usgs.gov/projects/SW_MoWS/index.shtml

Public Use? Yes

Off-the-shelf availability? More or less 
Does the model reside with the Developer or User? User

URL to access model:

http://wwwbrr.cr.usgs.gov/projects/SW_MoWS/software/oui_and_mms_s/prms.shtml

License Fees: Public domain

Other important model characteristics and model linkages:

Model Name: Multi-scale regional flow assessment tools:

PRMS - Precipitation runoff modeling system

LVDM - Landscape vegetative dynamic models

FMDS - Fish metapopulation dynamic simulation

Is this one model or a suite of interrelated models? If a suite, list the name of each model:

This is a suite of interrelated streamflow, landscape dynamic, and population dynamic models for evaluating the influence of changing land use and hydrology on stream fishes.

Dimensions, list planes for 1D to Quasi-3D, and time step(s) for interrelated models:

1D Quasi-2D 2D Quasi-3D 3D Time

PRMS operates on a daily and sub-daily basis.

LVDM operates on bi-weekly, seasonal, and annual time steps.

MPDS operates on a seasonal time step.

Color code all that apply:

1) Digital Conceptual Physical

2) Steady State Dynamic Conditions Statistical Simulation

3) Heuristic Decision-making Planning Operations

4) Cross-Section River Reach Sub-watershed Watershed State Region National

Platform Used (e.g., Windows, Mac, UNIX): Windows and UNIX

Purpose: To estimate the distribution and persistence of stream-dwelling fishes in response to changes in streamflow and land use.

Inputs:

PRMS: daily precipitation, and maximum and minimum temperature.

LVDM: remote sensed data from multiple sensing platforms and in situ data collection systems.

MPDS: fish species pool and their traits, stream channel morphological classes and sizes, seasonal discharge statistics- 10 day low, 10 day high, median, standard deviation.

Outputs:

PRMS outputs: distributed streamflow

LVDM outputs: Information on land cover type, vegetation biomass indices, vegetation condition (e.g., stress), surface water and soil moisture status that are used for input to hydrologic models and for linkage to habitat condition. 
MPDS outputs: stream segment - probability of fish species occupancy, fish species richness; subwatershed/ watershed - proportion of reaches occupied by fish species

Output Format Accessible by: Microsoft Windows Office Environment Yes or No ESRI ArcGIS Suite Yes or No

Spatial Extent of Solution and Minimum Mapping Unit or Cell Dimensions:

PRMS: user defined

LVDM: Spatial extent is the entire Upper Flint watershed. Cell dimensions range (depending on inputs) from 1 meter to 1000 meters on a side.

MPDS: Spatial extent is the Upper Flint River Basin with a MMU of a stream segment, depending on inputs.

Developer/Affiliation: USGS Upper Flint River Thrust Project Team

Current Users: Development team

Examples: NA

Supported at what location and by whom. Also, is support current? NA

Public Use? Not currently

Off-the-shelf availability? Not currently

Does the model reside with the Developer or User? Developer

URL to access model:

License Fees: None

Other important model characteristics and model linkages:

Model Name: River2D (River 2-Dimension)

Is this one model or a suite of interrelated models? If a suite, list the name of each model:

Dimensions, list planes for 1D to Quasi-3D, and time step(s) for interrelated models:

1D Quasi-2D 2D Quasi-3D 3D Time

Color code all that apply:

1) Digital Conceptual Physical

2) Steady State Dynamic Conditions Statistical Simulation

3) Heuristic Decision-making Planning Operations

4) Cross-Section River Reach Sub-watershed Watershed State Region National

Platform Used (e.g., Windows, Mac, UNIX): Windows

Purpose: Determining velocity and depths for estimating fish habitat. 
Inputs: Topography, discharge, downstream wse, eddy viscosity

Outputs: Velocity, depths, wse

Output Format Accessible by: Microsoft Windows Office Environment ESRI ArcGIS Suite

Yes or No

Yes or No

Spatial Extent of Solution and Minimum Mapping Unit or Cell Dimensions:

Developer/Affiliation: Peter Steffler, University of Alberta

Current Users (If many, list groups e.g., X District, U.S. Army Corps of Engineers):

Applied at what geographic locations, if many locations, provide broad example. Also, what publications/court cases/Environmental Impact Statements used this model?

Examples: Marmaton and Marais des Cygnes Rivers, west-central Missouri

Heimann, D.C., Richards, J.M., Brewer, S.K., and Norman, R.D., 2005, Quantification of Fish Habitat in selected reaches of the Marmaton and Marais des Cygnes Rivers, Missouri: U.S. Geological Survey, Scientific Investigations Report 2005-5180, 58 p.

Supported at what location and by whom. Also, is support current? (contact name, e-mail, phone number, mailing address)

Peter Steffler, University of Alberta

Public Use? Yes

Off-the-shelf availability? Yes

Does the model reside with the Developer or User?

URL to access model: http://www.river2d.ualberta.ca/

License Fees: None

Other important model characteristics and model linkages:

Model Name: RAX (River-Aquifer Exchange Calculator)

Is this one model or a suite of interrelated models? If a suite, list the name of each model:

Dimensions, list planes for 1D to Quasi-3D, and time step(s) for interrelated models:

1D Quasi-2D (longitudinal along river and vertical) 2D Quasi-3D 3D Time-depends on input, typically daily

Color code all that apply:

1) Digital Conceptual Physical

2) Steady State Dynamic Conditions Statistical Simulation

3) Heuristic Decision-making Planning Operations

4) Cross-Section River Reach Sub-watershed Watershed State Region National 
Platform Used (e.g., Windows, Mac, UNIX): Visual Basic within Excel (Windows or Mac)

Purpose: calculate time-series of flux (volume/time) of ground-water discharge to a river and spatial extent (meters of river bed) of the seepage zone and surface flow.

Inputs: time-series of aquifer recharge rate, upstream streamflow (boundary conditions), parameters describing aquifer geometry and hydraulic properties (valley width, slope, aquifer thickness, porosity, hydraulic conductivity)

Outputs: MS Excel table with ground-water discharge time-series and location of upstream extent of ground-water seepage.

Output Format Accessible by: Microsoft Windows Office Environment $\quad$ Yes or No ESRI ArcGIS Suite Yes or No

Spatial Extent of Solution and Minimum Mapping Unit or Cell Dimensions: User-specified extent of river

Developer/Affiliation: Chris Konrad, USGS

Current Users (If many, list groups e.g., X District, U.S. Army Corps of Engineers):

Applied at what geographic locations, if many locations, provide broad example. Also, what publications/court cases/Environmental Impact Statements used this model?

Examples: Konrad, C.P., Longitudinal hydraulic analysis of river-aquifer exchanges, Water Resources Research, 42 , W08425, doi: 10.1029/2005WR004197

Supported at what location and by whom. Also, is support current?

(contact name, e-mail, phone number, mailing address)

Chris Konrad, cpkonrad@usgs.gov, 206.343.4345 x 375, 1917 1 ${ }^{\text {st }}$ Ave, Seattle, WA 98101

Public Use? Available by request

Off-the-shelf availability? No

Does the model reside with the Developer or User? Yes

URL to access model:

License Fees:

Other important model characteristics and model linkages:

Model Name: RMA2/SED2D

Is this one model or a suite of interrelated models? If a suite, list the name of each model:

RMA2 can be used alone or as the hydraulic engine for SED2D

Dimensions, list planes for 1D to Quasi-3D, and time step(s) for interrelated models:

1D Quasi-2D 2D Quasi-3D 3D Time 
Color code all that apply:

1) Digital Conceptual Physical

2) Steady State Dynamic Conditions Statistical Simulation

3) Heuristic Decision-making Planning Operations

4) Cross-Section River Reach Sub-watershed Watershed State Region National

Platform Used (e.g., Windows, Mac, UNIX): Windows

Purpose:

RMA2-Determining flood inundation area, engine for SED2D sediment transport model

SED2D-Determining sediment transport, deposition, and erosion characteristics of riparian wetlands.

Inputs:

RMA2-Discharge, downstream wse, eddy viscosity

SED2D-particle size, sediment concentration

Outputs:

RMA2-Velocity, depths, wse

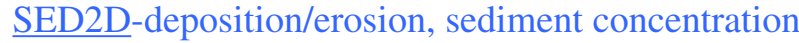

Output Format Accessible by: Microsoft Windows Office Environment $\quad$ Yes or No ESRI ArcGIS Suite $\quad$ Yes or No

Spatial Extent of Solution and Minimum Mapping Unit or Cell Dimensions:

Reach model, cell dimensions variable

Developer/Affiliation: U.S. Army Corps of Engineers

Current Users (If many, list groups e.g., X District, U.S. Army Corps of Engineers):

U.S. Army Corps of Engineers

Applied at what geographic locations, if many locations, provide broad example. Also, what publications/court cases/Environmental Impact Statements used this model?

Examples: Long Branch Creek, NE Missouri

Heimann, D.C., 2001, Numerical Simulation of Streamflow Distribution, Sediment Transport, and Sediment Deposition along Long Branch Creek in Northeast Missouri: U.S. Geological Survey, Water-Resources

Investigations Report 01-4269.

Supported at what location and by whom. Also, is support current?

(contact name, e-mail, phone number, mailing address)

USACE Waterways Experiment Station/Engineer Research and Development Center

Public Use? Yes

Off-the-shelf availability? Yes

Does the model reside with the Developer or User? Developer

URL to access model: 
License Fees: None

Other important model characteristics and model linkages: Used within the SMS pre-, post-processing software

Model Name: ROMS / CSTM (Regional Ocean Modeling System / Community Sediment Transport Model)

Is this one model or a suite of interrelated models? If a suite, list the name of each model:

Can be coupled with atmospheric and/or wave models.

Dimensions, list planes for 1D to Quasi-3D, and time step(s) for interrelated models:

1D Quasi-2D 2D Quasi-3D 3D Time

Color code all that apply:

1) Digital Conceptual Physical

2) Steady State Dynamic Conditions Statistical Simulation

3) Heuristic Decision-making Planning Operations Research

4) Cross-Section River Reach Sub-watershed Watershed State Region National

Platform Used (e.g., Windows, Mac, UNIX): All (Fortran90; requires CPP and various libraries. Parallelized on OpenMP and/or MPI).

Purpose: 3D Navier-Stokes equations finite difference model on S (terrain-following) vertical grid and curvilinear horizontal grid. Optimized for coastal modeling on $\sim 10 \mathrm{~m}$ to $10 \mathrm{~km}$ horiz. scales. Also does sediment transport and ecological (NPZ) models.

Inputs: Bathymetry, water elevations and/or flow, wind, waves, bottom sediment, sus. sediment, initial conditions

Outputs: 3D flow, turbulence parameters, sediment concentrations, bottom stratigraphy

Output Format Accessible by: Microsoft Windows Office Environment $\quad$ Yes or No

ESRI ArcGIS Suite Yes or No

Output is netCDF files in standard format. Many tools are available.

Spatial Extent of Solution and Minimum Mapping Unit or Cell Dimensions: Regional to global-scale domains;

minimum $\sim 0.1 \mathrm{~m}$.

Developer/Affiliation: ROMS/TOMS Group (Community development)

Current Users (If many, list groups e.g., X District, U.S. Army Corps of Engineers):

Many worldwide. Oceanographic researchers, mostly.

Applied at what geographic locations, if many locations, provide broad example. Also, what publications/court cases/Environmental Impact Statements used this model?

Examples:

Supported at what location and by whom. Also, is support current?

Supported by Rutgers Univ. and USGS.

No single contact. USGS users include:

Chris Sherwood-csherwood@usgs.gov 
Rich Signell - rsignell@usgs.gov

John Warner-jcwarner@usgs.gov

Public Use? Open-source under MIT/X style license (very non-restrictive)

Off-the-web availability? Yes (via Subersion source-code client)

Does the model reside with the Developer or User? Must be downloaded, compiled, set up, and run on user's computer.

URL to access model:

- https://www.myroms.org/projects/src/ Official ROMS Wiki/TRAC/SVN Site (Official repository for ROMS code; submit bug reports for ROMS and CSTM code here)

- https://www.myroms.org/wiki/ ROMS Documentation (including CSTM sediment-transport routines)

- https://www.myroms.org/forum/ ROMS Ocean Modeling Discussion Forum (queries and advice)

- http://www.ocean-modeling.org/ General ocean modeling web site

- https://www.myroms.org/projects/cstm/wiki CSTM TRAC/SVN Site (Repository for CSTM developers; code in trunk currently mirrors the official ROMS site, but it also has branches for CSTM project participants)

- https://www.hosted-projects.com/trac/cmgsoft/m_cmg/wiki Publicly available Matlab .m files from the USGS

- http://cstms.org Community sediment transport modeling system webpage

License Fees: Free

Other important model characteristics and model linkages: This model could be used for detailed modeling of river reaches, estuaries, lakes, and ocean waters, typically on reach to regional scales. It is not user friendly, but it is one of the better finite difference models for hydrostatic flow.

Model Name: SAC (Slope-Area Computation Program)

Is this one model or a suite of interrelated models? If a suite, list the name of each model:

Dimensions, list planes for 1D to Quasi-3D, and time step(s) for interrelated models:

1D Quasi-2D 2D Quasi-3D 3D Time

Color code all that apply:

1) Digital Conceptual Physical

2) Steady State Dynamic Conditions Statistical Simulation

3) Heuristic Decision-making Planning Operations

4) Cross-Section River Reach Sub-watershed Watershed State Region National

Platform Used (e.g., Windows, Mac, UNIX):

Purpose: Uses the standardized procedure for computing discharge by the slope-area method.

Inputs:

Outputs: 
Output Format Accessible by: Microsoft Windows Office Environment ESRI ArcGIS Suite
Yes or No

Yes or No

Spatial Extent of Solution and Minimum Mapping Unit or Cell Dimensions:

Developer/Affiliation:

Current Users (If many, list groups e.g., X District, U.S. Army Corps of Engineers):

Applied at what geographic locations, if many locations, provide broad example. Also, what publications/court cases/Environmental Impact Statements used this model?

Examples:

Supported at what location and by whom. Also, is support current?

(contact name, e-mail, phone number, mailing address)

Public Use?

Off-the-shelf availability?

Does the model reside with the Developer or User?

URL to access model: h2osoft@usgs.gov

http://water.usgs.gov/software/SAC/

http://pubs.er.usgs.gov/usgspubs/fs/fs20043028

License Fees:

Other important model characteristics and model linkages:

Model Name: SALMOD (Salmon Population Model)

Is this one model or a suite of interrelated models? If a suite, list the name of each model:

One model

Dimensions, list planes for 1D to Quasi-3D, and time step(s) for interrelated models:

1D Quasi-2D 2D Quasi-3D 3D Time step: Weekly

Color code all that apply:

1) Digital Conceptual Physical

2) Steady State Dynamic Conditions Statistical Simulation

3) Heuristic Decision-making Planning Operations

4) Cross-Section River Reach Sub-watershed Watershed State Region National

Platform Used (e.g., Windows, Mac, UNIX): Windows

Purpose: Estimating salmonid fish production as it varies with flow and temperature in a specific river reach.

Inputs: Number of spawning adults, flow, water temperature, habitat and flow relationships, habitat area and locations to characterize streams. 
Outputs: Number and biomass of various life stages of samonids, stream location, mortality and causes of developing fish, number and biomass of outmigrants

Output Format Accessible by: Microsoft Windows Office Environment Yes or No ESRI ArcGIS Suite Yes or No

Spatial Extent of Solution and Minimum Mapping Unit or Cell Dimensions: NA

Developer/Affiliation: USFWS/USGS FORT

Current Users (If many, list groups e.g., X District, U.S. Army Corps of Engineers):

U.S. Bureau of Reclamation, U.S. Fish and Wildlife Service, NOAA Fisheries, Bureau of Land Management, Hoopa, Karuk and Yurok Tribes, USGS, Consultants

Applied at what geographic locations, if many locations, provide broad example. Also, what publications/court cases/Environmental Impact Statements used this model?

Examples: Klamath, Sacramento, Trinity and Poudre Rivers

Reports and journal articles can be found by Google search

Supported at what location and by whom. Also, is support current? YES (contact name, e-mail, phone number, mailing address)

USGS-FORT, Sharon Campbell, campbells@usgs.gov,970-226-9331

Public Use? Yes

Off-the-shelf availability? Yes

Does the model reside with the Developer or User? User, through download from USGS FORT website

URL to access model: http://www.fort.usgs.gov/Products/Software/

License Fees: None - public domain

Other important model characteristics and model linkages: The fish production model was developed for the Trinity River Adaptive Management process, but has or is being applied in other rivers including the Klamath and the Sacramento.

Model Name: SalReP (Salmon Restoration Planning Model)

Is this one model or a suite of interrelated models? If a suite, list the name of each model:

One Model

Dimensions, list planes for 1D to Quasi-3D, and time step(s) for interrelated models:

1D Quasi-2D 2D Quasi-3D 3D Time Step: Daily

Color code all that apply:

1) Digital Conceptual Physical

2) Steady State Dynamic Conditions Statistical Simulation

3) Heuristic Decision-making Planning Operations

4) Cross-Section River Reach Sub-watershed Watershed State Region National 
Platform Used (e.g., Windows, Mac, UNIX): Windows

Purpose: Managing stream temperatures for fisheries restoration efforts

Inputs: Flow, temperature, meteorological conditions

Outputs: Flow and temperature

Output Format Accessible by: Microsoft Windows Office Environment $\quad$ Yes or No ESRI ArcGIS Suite Yes or No

Spatial Extent of Solution and Minimum Mapping Unit or Cell Dimensions: NA

Developer/Affiliation: USGS FORT

Current Users (If many, list groups e.g., X District, U.S. Army Corps of Engineers):

U.S. Fish and Wildlife Service, Bureau of Land Management

Applied at what geographic locations, if many locations, provide broad example. Also, what publications/court cases/Environmental Impact Statements used this model?

Examples: This modeling tool is specific to the Klamath River reaches between 3 hydropower dams or reservoirs (J.C. Boyle Dam and Copco Reserovir; Copco Dam and Iron Gate Reservoir). The model is in development.

Supported at what location and by whom. Also, is support current? YES

(contact name, e-mail, phone number, mailing address)

USGS-FORT, Sharon Campbell, campbells@usgs.gov,970-226-9331

Public Use? No

Off-the-shelf availability? No

Does the model reside with the Developer or User? Developer

URL to access model: None

License Fees: None

Other important model characteristics and model linkages: Beta test version of the model and documentation are available from USGS FORT on CD by request.

Model Name: SEDMOD (Mixed-Size Sediment Transport Model for Networks)

Is this one model or a suite of interrelated models? If a suite, list the name of each model:

Dimensions, list planes for 1D to Quasi-3D, and time step(s) for interrelated models:

$$
\text { 1D Quasi-2D 2D Quasi-3D 3D Time }
$$

Color code all that apply:

1) Digital Conceptual Physical

2) Steady State Dynamic Conditions Statistical Simulation 
3) Heuristic Decision-making Planning Operations

4) Cross-Section River Reach Sub-watershed Watershed State Region National

Platform Used (e.g., Windows, Mac, UNIX):

Purpose: A mathematical model for predicting the transport of mixed sizes of sediment by flow in networks of onedimensional open channels

Inputs:

Outputs:

Output Format Accessible by: Microsoft Windows Office Environment $\quad$ Yes or No ESRI ArcGIS Suite Yes or No

Spatial Extent of Solution and Minimum Mapping Unit or Cell Dimensions:

Developer/Affiliation:

Current Users (If many, list groups e.g., X District, U.S. Army Corps of Engineers):

Applied at what geographic locations, if many locations, provide broad example. Also, what publications/court cases/Environmental Impact Statements used this model?

Examples:

Supported at what location and by whom. Also, is support current?

(contact name, e-mail, phone number, mailing address)

Public Use?

Off-the-shelf availability?

Does the model reside with the Developer or User?

URL to access model: h2osoft@usgs.gov

http://wwwbrr.cr.usgs.gov/projects/SW_Math_mod/OpModels/download.htm

http://pubs.er.usgs.gov/usgspubs/wri/wri20014054

License Fees:

Other important model characteristics and model linkages:

Model Name: SEM (Structural Equation Model)

Is this one model or a suite of interrelated models? If a suite, list the name of each model:

One model

Dimensions, list planes for 1D to Quasi-3D, and time step(s) for interrelated models:

1D Quasi-2D 2D Quasi-3D 3D Time 
Color code all that apply:

1) Digital Conceptual Physical

2) Steady State Dynamic Conditions Statistical Simulation

3) Heuristic Decision-making Planning Operations

4) Cross-Section River Reach Sub-watershed Watershed State Region National

Platform Used (e.g., Windows, Mac, UNIX): all

Purpose: data analysis

Inputs: variance covariance matrices

Outputs: multivariate models

Output Format Accessible by: Microsoft Windows Office Environment $\quad$ Yes or No ESRI ArcGIS Suite Yes or No

Spatial Extent of Solution and Minimum Mapping Unit or Cell Dimensions:

Developer/Affiliation: numerous

Current Users (If many, list groups e.g., X District, U.S. Army Corps of Engineers):

Applied at what geographic locations, if many locations, provide broad example. Also, what publications/court cases/Environmental Impact Statements used this model?

Examples: Emap, published ecological studies.

Supported at what location and by whom. Also, is support current?

(contact name, e-mail, phone number, mailing address)

Bruce Pugesek

bpugesek@usgs.gov

406-994-6144

Northern Rocky Mountain Science Center

1648 S. $7^{\text {th }}$ St., MSU

Bozeman, MT 59717

Public Use? Yes

Off-the-shelf availability? Yes

Does the model reside with the Developer or User? User

URL to access model: Various vendors: EQS, MPlus, SAS, LISREL

License Fees: Yes

Other important model characteristics and model linkages: 
Model Name: SI3D (Semi-Implicit, 3D Model for Estuarine Circulation)

Is this one model or a suite of interrelated models? If a suite, list the name of each model:

Dimensions, list planes for 1D to Quasi-3D, and time step(s) for interrelated models:

1D Quasi-2D 2D Quasi-3D 3D Time

Color code all that apply:

1) Digital Conceptual Physical

2) Steady State Dynamic Conditions Statistical Simulation

3) Heuristic Decision-making Planning Operations

4) Cross-Section River Reach Sub-watershed Watershed State Region National

Platform Used (e.g., Windows, Mac, UNIX): Will run on all platforms

Purpose: Simulates 3D flows in rivers, lakes, reservoirs, bays, estuaries using a finite-difference, semi-implicit, leapfrog-trapezoidal numerical scheme.

Inputs: Bathymetry, boundary conditions, model parameters, wind

Outputs: Three components of velocity, water density, and salinity (if needed) at each model computational cell. A particle tracking code is also available, programmed in Java

Output Format Accessible by: Microsoft Windows Office Environment $\quad$ Yes or No ESRI ArcGIS Suite Yes or No

Spatial Extent of Solution and Minimum Mapping Unit or Cell Dimensions:

Minimum cell dimension is 1 meter

Developer/Affiliation: Peter E. Smith, USGS (retired)

Current Users (If many, list groups e.g., X District, U.S. Army Corps of Engineers): University of California Davis, Stanford University, Cornell University, University of Granda (Spain)

Applied at what geographic locations, if many locations, provide broad example. Also, what publications/court cases/Environmental Impact Statements used this model?

Examples: San Francisco Bay; Sacramento-San Joaquin River Delta, CA; Lake Tahoe, CA; Clear Lake, CA; Mono Lake, CA; Lake Erie; NY; other lakes

Supported at what location and by whom. Also, is support current? Support is somewhat limited because developer has retired from USGS; He can still be reached at his USGS contact information below

(contact name, e-mail, phone number, mailing address)

Peter E. Smith

pesmith@usgs.gov or pesmith07@comcast.net

916-278-3125

6000 J Street, Placer Hall

Sacramento, CA 95819-2605

Public Use? Yes

Off-the-shelf availability? Yes 
Does the model reside with the Developer or User? Developer

URL to access model: h2osoft@usgs.gov

http://pubs.usgs.gov/of/2006/1004/

http://www.sjrtmdl.org/technical/modeling/stanford_model.pdf

License Fees: None

Other important model characteristics and model linkages: Model pre- and post processing is done with Java software called Gr (see: http://ca.water.usgs.gov/program/sfbay/gr/). A 3D particle tracking code is also available.

Model Name: SIAM (Systems Impact Assessment Model)

Is this one model or a suite of interrelated models? If a suite, list the name of each model:

This decision support system has three component models, a water balance model (MODSIM), a water quality model (HEC-5Q) and a fish production model (SALMOD)

Dimensions, list planes for 1D to Quasi-3D, and time step(s) for interrelated models:

1D Quasi-2D 2D Quasi-3D 3D Time: $\begin{aligned} \text { MODSIM }=\text { Monthly } \\ \text { HEC-5Q }=\text { Daily } \\ \text { SALMOD }=\text { Weekly }\end{aligned}$

Color code all that apply:

1) Digital Conceptual Physical

2) Steady State Dynamic Conditions Statistical Simulation

3) Heuristic Decision-making Planning Operations

4) Cross-Section River Reach Sub-watershed Watershed State Region National

Platform Used (e.g., Windows, Mac, UNIX): Windows

Purpose: Evaluation and comparison of alternative water management scenarios

Inputs: Inflows to reservoirs, reservoir storage, meteorological conditions, water temperature, number of spawning salmon, habitat (weighted usable area) as it varies with flow for various life stages of salmonids

Outputs: Reservoir storage and water surface elevation, stream flows, fish production, mortality rates and partitioning among various causes, number and biomass of outmigrants from river reach

Output Format Accessible by: Microsoft Windows Office Environment $\quad$ Yes or No ESRI ArcGIS Suite Yes or No

Spatial Extent of Solution and Minimum Mapping Unit or Cell Dimensions: NA

Developer/Affiliation: SIAM - USGS FORT; MODSIM - Colorado State University; HEC-5Q - U.S. Army Corps of Engineers; SALMOD - USFWS/USGS FORT.

Current Users (If many, list groups e.g., X District, U.S. Army Corps of Engineers):

USGS; USFWS - California; Hoopa, Yurok, and Karuk Tribes; NOAA, Utah State University

Applied at what geographic locations, if many locations, provide broad example. Also, what publications/court cases/Environmental Impact Statements used this model? 
Examples: Klamath River from Upper Klamath Lake, OR downstream to the Pacific Ocean. Being used as part of Klamath Hydropower relicensing and by the Klamath Settlement Negotiations Work Group.

Bartholow, J.M. 2005. Recent Water Temperature Trends in the Lower Klamath River, California. North American Journal of Fisheries Management 25(1): 152-162.

Flug, M. and S.G. Campbell. 2003. Drought Allocation Modeling For the Klamath River. In: 2nd International Water Congress: Watershed Management for Water Supply Systems; CD ROM format, American Water Resources Association (AWRA), New York, NY. June 29 - July 3, 2003. 6 pp.

Bartholow, J., S.G. Campbell, and M. Flug. 2004. Predicting the Thermal Effects of Dam Removal on the Klamath River. Environmental Management, Vol. 34, No. 6, Dec., pp. 856-874.

Flug, M. and S.G. Campbell. 2005. Drought Allocations Using the Systems Impact Assessment Model: Klamath River. Journal of Water Resources Planning and Management, ASCE, Vol. 131, No. 2, Mar./Apr., pp. 110-115.

Campbell, S.G., R.B. Hanna, M. Flug, and J.F. Scott. 2001. Modeling Klamath River System Operations for Quantity and Quality. Journal of Water Resources Planning and Management, Vol. 127, No. 5, pp 284-294.

Supported at what location and by whom. Also, is support current? Yes (contact name, e-mail, phone number, mailing address)

USGS-FORT, Sharon Campbell, campbells@usgs.gov,970-226-9331

Public Use? Yes

Off-the-shelf availability? Yes, available for download from USGS FORT website along with documentation

Does the model reside with the Developer or User? User - through download

URL to access model: http://www.fort.usgs.gov/Products/Software/

License Fees: None - public domain

Other important model characteristics and model linkages: This model was designed as a decision support system to allow resource managers to evaluate water management alternatives affecting fall Chinook salmon populations in the Klamath River below 4 hydropower dams. The model simulates flow, reservoir storage and water surface elevations, water temperature and fish production values. The model currently has a 45 year period of record for historical flow and both water and air temperature.

Model Name: SNTEMP (Stream Network Temperature Model)

Is this one model or a suite of interrelated models? If a suite, list the name of each model:

One Model

Dimensions, list planes for 1D to Quasi-3D, and time step(s) for interrelated models: 1D Quasi-2D 2D Quasi-3D 3D Time Step: Daily

Color code all that apply:

1) Digital Conceptual Physical

2) Steady State Dynamic Conditions Statistical Simulation

3) Heuristic Decision-making Planning Operations 
4) Cross-Section River Reach Sub-watershed Watershed State Region National

Platform Used (e.g., Windows, Mac, UNIX): DOS

Purpose: Simulation stream water temperatures

Inputs: Flow, meteorological conditions, temperature

Outputs: Stream temperature

Output Format Accessible by: Microsoft Windows Office Environment $\quad$ Yes or No ESRI ArcGIS Suite Yes or No

Spatial Extent of Solution and Minimum Mapping Unit or Cell Dimensions: NA

Developer/Affiliation: USFWS/USGS FORT

Current Users (If many, list groups e.g., X District, U.S. Army Corps of Engineers):

Widely used by many organizations

Applied at what geographic locations, if many locations, provide broad example. Also, what publications/court cases/Environmental Impact Statements used this model?

Examples: Trinity, Klamath Rivers among many others.

Anderson, C.W., and Carpenter, K.D., 1998, Water quality and algal conditions in the North Umpqua River Basin, Oregon, 1992-95, and implications for resource management. USGS Water Resources Investigations Report 98$4125.95 \mathrm{pp}$.

Bartholow, J.M. 2002. SNTEMP (In)Frequently Asked Questions.

Bartholow, J.M. 2002. Modeling Uncertainty: Quicksand For Water Temperature Modeling.

Bartholow, J.M. 2000. The Stream Segment and Stream Network Temperature Models: A Self-Study Course, Version 2.0. U.S. Geological Survey Open File Report 99-112. 276 pp.

Bartholow, J.M., 2000, Estimating cumulative effects of clearcutting on stream temperatures, Rivers, 7(4), $284-297$.

Bartholow, J.M. 1993. Sensitivity of the U.S. Fish and Wildlife Service's Stream Network Temperature Model. Pages 247-257 in Morel-Seytoux, ed., Proceedings of the Thirteenth Annual American Geophysical Union Hydrology Days. Fort Collins, CO.

Bartholow, J.M. 1991. A modeling assessment of the thermal regime for an urban sport fishery. Environmental Management. 15(6):833-845.

Bartholow, J.M. 1990. Stream temperature model. Pages IV-20 to IV-47 in W.S. Platts ed. Managing Fisheries and Wildlife on Rangelands Grazed by Livestock: A guidance and reference document for biologists. W.S. Platts and Assoc. for the Nevada Department of Wildlife. December, 1990. v.p.

Bartholow, J.M. 1989. Stream temperature investigations: field and analytic methods. Instream Flow Information Paper No. 13. U.S. Fish Wildl. Serv. Biol. Rep. 89(17). 139 pp.

Bartholow, J.M., J.L. Laake, C.B. Stalnaker, and S.C. Williamson. 1993. A salmonid population model with emphasis on habitat limitations. Rivers 4(4). 
Supported at what location and by whom. Also, is support current? NO

(contact name, e-mail, phone number, mailing address)

USGS-FORT, Sharon Campbell, campbells@usgs.gov, 970-226-9331

Public Use? Yes

Off-the-shelf availability? Yes

Does the model reside with the Developer or User? User, through download from USGS FORT website

URL to access model: http://www.fort.usgs.gov/Products/Software/

License Fees: None - public domain

Other important model characteristics and model linkages: John Bartholow, USGS FORT is retired and support for this model is very limited.

Model Name: SPARROW (SPAtially Referenced Regressions On Watershed Attributes)

Is this one model or a suite of interrelated models? If a suite, list the name of each model:

Dimensions, list planes for 1D to Quasi-3D, and time step(s) for interrelated models:

1D Quasi-2D 2D Quasi-3D 3D Time

Color code all that apply:

1) Digital Conceptual Physical

2) Steady State Dynamic Conditions Statistical Simulation

3) Heuristic Decision-making Planning Operations

4) Cross-Section River Reach Sub-watershed Watershed State Region National

Platform Used (e.g., Windows, Mac, UNIX):

Purpose: Uses spatially referenced regressions of contaminant transport on watershed attributes to support regional water-quality assessment goals.

Inputs:

Outputs:

Output Format Accessible by: Microsoft Windows Office Environment $\quad$ Yes or No ESRI ArcGIS Suite Yes or No

Spatial Extent of Solution and Minimum Mapping Unit or Cell Dimensions:

Developer/Affiliation:

Current Users (If many, list groups e.g., X District, U.S. Army Corps of Engineers):

Applied at what geographic locations, if many locations, provide broad example. Also, what publications/court cases/Environmental Impact Statements used this model? 
Examples:

Supported at what location and by whom. Also, is support current?

(contact name, e-mail, phone number, mailing address)

Public Use?

Off-the-shelf availability?

Does the model reside with the Developer or User?

URL to access model: h2osoft@usgs.gov

http://water.usgs.gov/nawqa/sparrow/sparrow-mod.html

http://water.usgs.gov/nawqa/sparrow

License Fees:

Other important model characteristics and model linkages:

Model Name: SToRM (ㅌystem for Transport and River Modeling)

Is this one model or a suite of interrelated models? If a suite, list the name of each model:

This is a single model, but it is distributed as part of a graphical user interface, MD_SWMS, that contains other models.

Dimensions, list planes for 1D to Quasi-3D, and time step(s) for interrelated models:

1D Quasi-2D 2D Quasi-3D 3D Time

Color code all that apply:

1) Digital Conceptual Physical

2) Steady State Dynamic Conditions Statistical Simulation

3) Heuristic Decision-making Planning Operations

4) Cross-Section River Reach Sub-watershed Watershed State Region National

Platform Used (e.g., Windows, Mac, UNIX): Windows

Purpose: river flow modeling, including flood plains and watersheds

Inputs: bathymetry with corresponding skin roughness coefficients, wind, flow discharge, and river stage

Outputs: flow depths and velocities

Output Format Accessible by: Microsoft Windows Office Environment Yes or No ESRI ArcGIS Suite $\quad$ Yes or No

Spatial Extent of Solution and Minimum Mapping Unit or Cell Dimensions: millimiters to kilometers

Developer/Affiliation: USGS Geomorphology and Sediment Transport Laboratory, 4620 Technology Drive, Suite 400, Golden, CO 80403

Current Users (If many, list groups e.g., X District, U.S. Army Corps of Engineers): Program is under development, with first training course and subsequent distribution scheduled for last week in April 
Applied at what geographic locations, if many locations, provide broad example. Also, what publications/court cases/Environmental Impact Statements used this model?

Examples: Flint River, GA; Trinity River (Northern California)

Supported at what location and by whom. Also, is support current? Yes (contact name, e-mail, phone number, mailing address)

Francisco J.M. Simões, USGS Geomorphology and Sediment Transport Laboratory, 4620 Technology Drive, Suite 400, Golden, CO 80403, Ph. (303)278-7956, frsimoes@usgs.gov

Public Use? Yes

Off-the-shelf availability? Yes

Does the model reside with the Developer or User?

URL to access model: http://wwwbrr.cr.usgs.gov/gstl/

License Fees: None

Other important model characteristics and model linkages: SToRM is a 2D depth-averaged model. It uses an unstructured grid (triangles), and it includes steady state and time dependent capabilities. SToRM was specially developed for river flows with flood plains and it incorporates an overland flow algorithm, which means that it can be used at the watershed scale. It can deal with supercritical flows, regime transitions (e.g., hydraulic jumps), has wetting and drying capabilities, can model flood inundation over dry or wet areas, flow through vegetation, and it also includes wind-driven effects. The model is distributed as part of a larger package, MD_SWMS, which is a graphical user interface for data pre- and post-processing. MD_SWMS also incorporates other models, such as the FASTMECH model.

Model Name: StreamStats

Is this one model or a suite of interrelated models? If a suite, list the name of each model:

Dimensions, list planes for 1D to Quasi-3D, and time step(s) for interrelated models:

1D Quasi-2D 2D Quasi-3D 3D Time

Color code all that apply:

1) Digital Conceptual Physical

2) Steady State Dynamic Conditions Statistical Simulation

3) Heuristic Decision-making Planning Operations

4) Cross-Section River Reach Sub-watershed Watershed State Region National

Platform Used (e.g., Windows, Mac, UNIX):

Purpose: Web-based tool that allows users to obtain streamflow statistics and basin characteristics.

Inputs:

Outputs:

Output Format Accessible by: Microsoft Windows Office Environment $\quad$ Yes or No ESRI ArcGIS Suite Yes or No 
Spatial Extent of Solution and Minimum Mapping Unit or Cell Dimensions:

Developer/Affiliation:

Current Users (If many, list groups e.g., X District, U.S. Army Corps of Engineers):

Applied at what geographic locations, if many locations, provide broad example. Also, what publications/court cases/Environmental Impact Statements used this model?

Examples:

Supported at what location and by whom. Also, is support current?

(contact name, e-mail, phone number, mailing address)

Kernell Ries, USGS (kries@usgs.gov)

Public Use?

Off-the-shelf availability?

Does the model reside with the Developer or User?

URL to access model: http://water.usgs.gov/osw/streamstats/

License Fees:

Other important model characteristics and model linkages:

Model Name: SWIFT2D (Surface-Water Integrated Flow and Transport 2D Model)

Is this one model or a suite of interrelated models? If a suite, list the name of each model:

Dimensions, list planes for 1D to Quasi-3D, and time step(s) for interrelated models:

1D Quasi-2D 2D Quasi-3D 3D Time

Color code all that apply:

1) Digital Conceptual Physical

2) Steady State Dynamic Conditions Statistical Simulation

3) Heuristic Decision-making Planning Operations

4) Cross-Section River Reach Sub-watershed Watershed State Region National

Platform Used (e.g., Windows, Mac, UNIX):

Purpose: Simulation of 2D flow and constituent transport in vertically well-mixed estuaries, tidal embayments, and inland waterways using finite-difference methods. Water-quality computations can treat reactive and (or) conservative constituents simultaneously.

Inputs:

Outputs:

Output Format Accessible by: Microsoft Windows Office Environment $\quad$ Yes or No ESRI ArcGIS Suite Yes or No 
Spatial Extent of Solution and Minimum Mapping Unit or Cell Dimensions:

Developer/Affiliation:

Current Users (If many, list groups e.g., X District, U.S. Army Corps of Engineers):

Applied at what geographic locations, if many locations, provide broad example. Also, what publications/court cases/Environmental Impact Statements used this model?

Examples:

Supported at what location and by whom. Also, is support current?

(contact name, e-mail, phone number, mailing address)

Public Use?

Off-the-shelf availability?

Does the model reside with the Developer or User?

URL to access model: h2osoft@usgs.gov

http://pubs.usgs.gov/tm/2005/tm6bl/

License Fees:

Other important model characteristics and model linkages:

Model Name: SWSTAT (Surface Water Statistics)

Is this one model or a suite of interrelated models? If a suite, list the name of each model:

Dimensions, list planes for 1D to Quasi-3D, and time step(s) for interrelated models:

1D Quasi-2D 2D Quasi-3D 3D Time

Color code all that apply:

1) Digital Conceptual Physical

2) Steady State Dynamic Conditions Statistical Simulation

3) Heuristic Decision-making Planning Operations

4) Cross-Section River Reach Sub-watershed Watershed State Region National

Platform Used (e.g., Windows, Mac, UNIX):

Purpose: Contains a number of options for statistically analyzing time-series data.

Inputs:

Outputs:

Output Format Accessible by: Microsoft Windows Office Environment $\quad$ Yes or No ESRI ArcGIS Suite Yes or No 
Spatial Extent of Solution and Minimum Mapping Unit or Cell Dimensions:

Developer/Affiliation:

Current Users (If many, list groups e.g., X District, U.S. Army Corps of Engineers):

Applied at what geographic locations, if many locations, provide broad example. Also, what publications/court cases/Environmental Impact Statements used this model?

Examples:

Supported at what location and by whom. Also, is support current?

(contact name, e-mail, phone number, mailing address)

Public Use?

Off-the-shelf availability?

Does the model reside with the Developer or User?

URL to access model: h2osoft@usgs.gov

http://water.usgs.gov/software/SWSTAT/

License Fees:

Other important model characteristics and model linkages:

Model Name: TRIMR2D (Transient Inundation Model for Rivers - 2 Dimensional)

Is this one model or a suite of interrelated models? If a suite, list the name of each model:

Dimensions, list planes for 1D to Quasi-3D, and time step(s) for interrelated models:

1D Quasi-2D 2D Quasi-3D 3D Time

Color code all that apply:

1) Digital Conceptual Physical

2) Steady State Dynamic Conditions Statistical Simulation

3) Heuristic Decision-making Planning Operations

4) Cross-Section River Reach Sub-watershed Watershed State Region National

Platform Used (e.g., Windows, Mac, UNIX):

Purpose: Simulates flow in a channel and/or floodplain using a structured grid, semi-implicit, semi-Lagrangian, finite-difference, and depth averaged for steady and unsteady flows.

Inputs:

Outputs:

Output Format Accessible by: Microsoft Windows Office Environment $\quad$ Yes or No

ESRI ArcGIS Suite Yes or No


Spatial Extent of Solution and Minimum Mapping Unit or Cell Dimensions:

Developer/Affiliation:

Current Users (If many, list groups e.g., X District, U.S. Army Corps of Engineers):

Applied at what geographic locations, if many locations, provide broad example. Also, what publications/court cases/Environmental Impact Statements used this model?

Examples:

Supported at what location and by whom. Also, is support current?

(contact name, e-mail, phone number, mailing address)

Public Use?

Off-the-shelf availability?

Does the model reside with the Developer or User?

URL to access model: h2osoft@usgs.gov

http://pubs.usgs.gov/of/2003/ofr03371/

License Fees:

Other important model characteristics and model linkages:

Model Name: UNTRIM (Unstructured, Tidal, Residual, and Intertidal Mudflat)

Is this one model or a suite of interrelated models? If a suite, list the name of each model:

Dimensions, list planes for 1D to Quasi-3D, and time step(s) for interrelated models:

1D Quasi-2D 2D Quasi-3D 3D Time

Color code all that apply:

1) Digital Conceptual Physical

2) Steady State Dynamic Conditions Statistical Simulation

3) Heuristic Decision-making Planning Operations

4) Cross-Section River Reach Sub-watershed Watershed State Region National

Platform Used (e.g., Windows, Mac, UNIX):

Purpose: Simulates flow in a channel and/or floodplain using an unstructured grid, semi-implicit, semi-Lagrangian, finite-difference, and depth averaged for steady and unsteady flows.

Inputs:

Outputs:

Output Format Accessible by: Microsoft Windows Office Environment $\quad$ Yes or No

ESRI ArcGIS Suite Yes or No


Spatial Extent of Solution and Minimum Mapping Unit or Cell Dimensions:

Developer/Affiliation:

Current Users (If many, list groups e.g., X District, U.S. Army Corps of Engineers):

Applied at what geographic locations, if many locations, provide broad example. Also, what publications/court cases/Environmental Impact Statements used this model?

Examples:

Supported at what location and by whom. Also, is support current?

(contact name, e-mail, phone number, mailing address)

Public Use?

Off-the-shelf availability?

Does the model reside with the Developer or User?

URL to access model: h2osoft@usgs.gov

http://sfports.wr.usgs.gov/

License Fees:

Other important model characteristics and model linkages:

Model Name: VPV (The Velocity Profile Viewer)

Is this one model or a suite of interrelated models? If a suite, list the name of each model:

Dimensions, list planes for 1D to Quasi-3D, and time step(s) for interrelated models:

1D Quasi-2D 2D Quasi-3D 3D Time

Color code all that apply:

1) Digital Conceptual Physical

2) Steady State Dynamic Conditions Statistical Simulation

3) Heuristic Decision-making Planning Operations

4) Cross-Section River Reach Sub-watershed Watershed State Region National

Platform Used (e.g., Windows, Mac, UNIX):

Purpose: Visualizing time series of velocity profiles

Inputs:

Outputs:

Output Format Accessible by: Microsoft Windows Office Environment ESRI ArcGIS Suite

Yes or No

Yes or No

Spatial Extent of Solution and Minimum Mapping Unit or Cell Dimensions: 
Developer/Affiliation:

Current Users (If many, list groups e.g., X District, U.S. Army Corps of Engineers):

Applied at what geographic locations, if many locations, provide broad example. Also, what publications/court cases/Environmental Impact Statements used this model?

Examples:

Supported at what location and by whom. Also, is support current? (contact name, e-mail, phone number, mailing address)

John Donovan, USGS (jmd@usgs.gov)

Public Use?

Off-the-shelf availability?

Does the model reside with the Developer or User?

URL to access model: http://ca.water.usgs.gov/program/sfbay/vpv/

License Fees:

Other important model characteristics and model linkages:

Model Name: WRRAT (Wood River Resource Analysis Tool)

Is this one model or a suite of interrelated models? If a suite, list the name of each model:

One model

Dimensions, list planes for 1D to Quasi-3D, and time step(s) for interrelated models: Model is areal - it is a land use model.

$$
\text { 1D Quasi-2D 2D Quasi-3D 3D Time }
$$

Color code all that apply:

1) Digital Conceptual Physical

2) Steady State Dynamic Conditions Statistical Simulation Areal

3) Heuristic Decision-making Planning Operations

4) Cross-Section River Reach Sub-watershed Watershed State Region National

Platform Used (e.g., Windows, Mac, UNIX): Windows

Purpose: Estimating cost/benefits of various best management practices for nutrient loading reduction.

Inputs: Land parcels, stream corridors, BMP costs

Outputs: Relative nutrient loading index, costs for BMP implementation and maintainence

Output Format Accessible by: Microsoft Windows Office Environment $\quad$ Yes or No ESRI ArcGIS Suite Yes or No

Spatial Extent of Solution and Minimum Mapping Unit or Cell Dimensions: Land parcel 
Developer/Affiliation: USGS FORT

Current Users (If many, list groups e.g., X District, U.S. Army Corps of Engineers):

None - model is still in development. Future users may include the Klamath Basin Rangeland Trust and Wood River Valley Ranchers Association members

Applied at what geographic locations, if many locations, provide broad example. Also, what publications/court cases/Environmental Impact Statements used this model?

Examples: Wood River Valley, Oregon

Supported at what location and by whom. Also, is support current? Yes

(contact name, e-mail, phone number, mailing address)

USGS-FORT, Sharon Campbell, campbells@usgs.gov,970-226-9331

Public Use? No

Off-the-shelf availability? No

Does the model reside with the Developer or User? Developer

URL to access model: None

License Fees: None - model will be in the public domain

Other important model characteristics and model linkages: Beta test version of model and documentation is available on CD from USGS FORT contact upon request.

Model Name: WSPRO (Water-Surface PROfile Computations)

Is this one model or a suite of interrelated models? If a suite, list the name of each model:

Dimensions, list planes for 1D to Quasi-3D, and time step(s) for interrelated models:

1D Quasi-2D 2D Quasi-3D 3D Time

Color code all that apply:

1) Digital Conceptual Physical

2) Steady State Dynamic Conditions Statistical Simulation

3) Heuristic Decision-making Planning Operations

4) Cross-Section River Reach Sub-watershed Watershed State Region National

Platform Used (e.g., Windows, Mac, UNIX):

Purpose: Computes water-surface profiles for subcritical, critical, or supercritical flow as long as the flow can be reasonably classified as one-dimensional, gradually-varied, steady flow.

Inputs:

Outputs:

Output Format Accessible by: Microsoft Windows Office Environment $\quad$ Yes or No ESRI ArcGIS Suite Yes or No 
Spatial Extent of Solution and Minimum Mapping Unit or Cell Dimensions:

Developer/Affiliation:

Current Users (If many, list groups e.g., X District, U.S. Army Corps of Engineers):

Applied at what geographic locations, if many locations, provide broad example. Also, what publications/court cases/Environmental Impact Statements used this model?

Examples:

Supported at what location and by whom. Also, is support current?

(contact name, e-mail, phone number, mailing address)

Jorge Pagan, FHWY (jorge.pagan@fhwa.dot.gov)

Public Use?

Off-the-shelf availability?

Does the model reside with the Developer or User?

URL to access model: h2osoft@usgs.gov

http://water.usgs.gov/software/WSPRO/

http://www.fhwa.dot.gov/engineering/hydraulics/software/wsproman.pdf

License Fees:

Other important model characteristics and model linkages:

Publishing support provided by:

Denver Publishing Service Center

For more information concerning this publication, contact:

Center Director, USGS Fort Collins Science Center

2150 Centre Ave., Bldg. C

Fort Collins, CO 80526-8118

(970)226-9398

Or visit the Fort Collins Science Center Web site at:

http://www.fort.usgs.gov/ 
